\title{
Chemosensory conditioning in molluscs: I. Failure of contextual conditioning in Hermissenda
}

\author{
IKSUNG JIN, HAOJIANG HUANG, JAE-IL KIM, and JOSEPH FARLEY \\ Indiana University, Bloomington, Indiana
}

\begin{abstract}
Aversive chemosensory conditioning alters Hermissenda's feeding behavior. But opposite behavioral changes have been reported, depending on whether discrete-trial or context-conditioning paradigms were used, raising questions about the roles of associative and nonassociative processes. We attempted to produce chemosensory contextual conditioning but failed to do so across a wide range of conditions. In Experiments 1-3, we observed large, nonspecific bite latency increases to shellfish extracts, regardless of whether they had signaled the presence or absence of shaking. In Experiment 4, we found that mere exposure to shellfish extract produced latency increases; vestibular stimulation was unnecessary. In a final experiment, using Y-maze choice tests, we failed to observe selective reductions in animals' preference for shellfish paired with shaking. Nonassociative processes stemming from prolonged exposure to concentrated shellfish extracts appear to be major factors in our failure to demonstrate associative chemosensory contextual conditioning.
\end{abstract}

Many organisms learn what, and what not, to eat on the basis of the consequences that are associated with ingestion of specific foods (Barker, Best, \& Domjan, 1977; Garcia, Kimmeldorf, \& Koelling, 1955). Modification of ingestive behavior has formed the basis for several powerful demonstrations of associative learning in a variety of vertebrate (Riley \& Tuck, 1985) and invertebrate (Cowan \& Siegel, 1986) species.

Learned changes in the feeding behaviors of many species of gastropod (Alexander, Audesirk, \& Audesirk, 1982; Kemenes \& Benjamin, 1989; Mpitsos, Collins, \& McClellan, 1978; Mpitsos \& Davis, 1973; Whelan \& McCrohan, 1996) and pulmonate (Croll \& Chase, 1977, 1980; Peschel, Straub, \& Teyke, 1996; Suzuki, 1968) molluscs have been reported. Particularly clear and robust examples have been provided using chemosensory aversion-learning paradigms (Gelperin, 1975; Mpitsos \& Davis, 1973). The ease with which changes in feeding behavior can be produced in molluscs by associative learning and their large, hardy, identifiable neurons provide a strong rationale for their continued use in efforts to uncover causative neurophysiological changes that mediate associative learning and memory storage processes involved in adaptive food selection.

I.J. and H.H. both contributed equally to this research and were affiliated with the Program in Neural Science at Indiana University, Bloomington. J.-I.K., who also was affiliated with the Program in Neural Science at Indiana University, was killed in an automobile accident on May 31,1999 . We dedicate both this article and the one that follows to him. Correspondence concerning this article should be addressed to J. Farley, Graduate Programs in Neural Science and Biochemistry, Indiana University, Bloomington, IN 47405-7007 (e-mail: farleyj@indiana.edu).
These considerations led us to develop a discrete-trial chemosensory aversion learning procedure for the nudibranch Hermissenda crassicornis (Farley et al., 1990; Farley, Reasoner, \& Janssen, 1997), employing the same unconditioned stimulus (US) as that used in prior studies of associative phototactic suppression (Crow \& Alkon, 1978; Farley \& Alkon, 1980, 1982). With this procedure, an animal's ingestive behavior, measured as its bite-strike response to a proffered food, was suppressed for several days following pairings of the food extract (conditioned stimulus, CS +) with rotation-produced vestibular stimulation. This suppression was largely, although not completely, specific to the pairing procedure, as well as to the trained food. As for all other examples of aversive conditioning with molluscs that we are aware of, pairing a food extract with a presumptive aversive stimulus led to a large reduction in ingestive behavior directed toward that food CS and active withdrawal in many subjects.

Most studies of associative modification of feeding behavior in molluscs have used discrete presentations of chemosensory stimuli as CSs. In recognition of the fact that the background stimuli that define an experimental environment often can have profound effects on both the acquisition and the expression of associations within that context (e.g., Balsam \& Tomie, 1985), several investigators have examined the capacity of various molluscs to form associations between an aversive US and the context in which it is presented. Results consistent with the successful occurrence of contextual/environmental conditioning have been reported for both Aplysia (Colwill, Absher, \& Roberts, 1988) and Helix (Balaban \& Bravarenko, 1993).

Chemosensory contextual conditioning has also been reported for Hermissenda (Rogers, Schiller, \& Matzel, 
1996). Animals exposed to a distinctive environmentdefined by scallop extract - that signaled turbulence later showed small $(\sim 0.5 \mathrm{sec})$ but statistically significant $d e-$ creases in their bite-strike latencies toward scallop. Successful conditioning was obtained only when scallop, but not shrimp, was used as the contextual cue. We were surprised at this reported decrease in bite-strike latencies by Rogers et al. for two reasons. First, in our prior studies, we observed that discrete-trial pairings of shellfish extract $\mathrm{CS}+\mathrm{s}$ with rotation led to large increases in bitestrike latencies (Farley et al., 1990; Farley et al., 1997). Second, as has already been noted, all other reports of aversive chemosensory conditioning with molluscs have also shown response latency increases to $\mathrm{CS}+$.

Rogers et al.'s (1996) report was, with two exceptions, patterned after our earlier study (Farley et al., 1990). Whereas we had used relatively brief $(30-\mathrm{sec})$ discrete-trial shellfish extract stimulation as the $\mathrm{CS}+$, Rogers et al. used prolonged (25-min) continuous exposure to shellfish extract as their context $\mathrm{CS}+$. In addition, we had used 30 -sec unidirectional turntable stimulation as the US, whereas Rogers et al. used brief (3-sec) orbital rotation (shaking) as a US. Thus, we were intrigued by the possibility that these procedural differences, alone or in combination, might be so critical as to change the qualitative character of the learned response to $\mathrm{CS}+$. Another reason for our reexamination of contextual chemosensory conditioning concerns the relatively simple contextual CS used. In other demonstrations of context conditioning with invertebrates, multiple stimuli made up the context CS. Hence, it was not determined which stimulus cues/dimensions controlled the animals' behavior. The use of food extracts to distinguish environments is a convenient simplification that should facilitate cellular studies of context conditioning in reduced preparations. A prerequisite for such studies in Hermissenda is a more thorough behavioral characterization and determination of those stimulus and training parameters that maximize the reliability and robustness of this form of learning in intact animals.

Thus, a specific goal of the present study was to determine whether the method of presenting the chemosensory CS (discrete vs. continuous presentation) and/or the type of US used (extended turntable vs. brief orbital rotation) would influence the nature of the change in ingestive behavior that emerged during chemosensory conditioning. As a first step, we attempted to replicate the principal findings reported by Rogers et al. (1996).

\section{EXPERIMENTS 1-3}

In Experiments 1-3, we investigated whether Hermissenda could learn an association between an aversive US (orbital rotation) and the context in which that US was presented, by replicating the discrimination-learning procedure described in Experiment 1 of Rogers et al. (1996). The general training procedure involved exposure of animals to two different chemosensory contexts defined by the presence of either scallop or shrimp extract. For each animal, one context $(\mathrm{CS}+)$ was reinforced by repeated brief presentations of orbital rotation (shaking), whereas the second context (CS-) was never paired with the US. The latencies of Hermissenda's bite-strike behaviors, elicited by and directed toward small pieces of the shellfish meat that had served as the sources of the CS+ and CS - chemosensory extracts, were measured before and after training. To the degree that the animals responded differently to CS + versus CS - after training, this would constitute necessary (although not sufficient) evidence for inferring that the animals had learned an association between CS + and the orbital rotation US. The expected outcome, based on the report of Rogers et al., was that the animals would exhibit moderate posttraining response latency increases to CS $-(\sim 1.0-1.5 \mathrm{sec}$, relative increases of $\sim 40 \%-60 \%$ ) but small response latency decreases to CS $+(\sim 0.5-1.0 \mathrm{sec}$, relative decreases of $\sim 20 \%-40 \%)$.

\section{Method}

\section{Subjects}

Adult Hermissenda crassicornis were collected by Sea Life Supply Co. (Sand City, CA) and shipped to Indiana University, where 20-35 animals were housed in individual flow-through containers in 50-gallon refrigerated $\left(14^{\circ} \mathrm{C}\right)$ recirculating artificial seawater (ASW) aquaria (Farley et al., 1990; Farley et al., 1997). The animals were maintained in the laboratory for 3-6 days on a 12:12-h light:dark cycle before use. All training and testing of the animals were conducted during the intermediate $8 \mathrm{~h}$ of their 12-h daylight cycle. Fifty animals were used in Experiments 1-3.

Prior to an experiment, the animals were fed daily with small pieces of Hikari Gold fish food. Feedings were discontinued $48 \mathrm{~h}$ before the initial measurement of feeding reflexes and the 1st day of conditioning. In Experiments 1 and 2, the animals received no supplemental feedings once behavioral training had begun, as in previous (Farley et al., 1990; Farley et al., 1997) discrete-trial studies. In Experiment 3, the animals were fed at the end of each day ( $\sim \mathrm{h}$ after training) with small pieces of fish food, as described in Rogers et al. (1996).

\section{Apparatus}

As in previous studies (Farley et al., 1990; Farley et al., 1997; Rogers et al., 1996), chemosensory testing of individual animals was conducted in plastic Petri dishes, $9.0 \mathrm{~cm}$ in diameter and filled to a height of $\sim 1.0 \mathrm{~cm}$ with refrigerated ASW. The Petri dishes were rinsed, scrubbed with hot top water, and filled with fresh ASW between each test trial. All behavioral tests were recorded on videotape with a tripod-mounted video camera and a zoom lens (Panasonic WV $1300 \mathrm{~A}$ ).

The conditioning apparatus consisted of an orbital rotator (TEKpro Tec-Tator, model R4139-5), to which a clear round Plexiglas chamber $(12 \mathrm{~cm}$ in diameter, $4.5 \mathrm{~cm}$ in height) full of ASW was attached. Within this Plexiglas chamber, 4-6 Hermissenda were placed, each confined within a clear plastic scintillation vial $(2.25 \mathrm{~cm}$ in diameter, $4.5 \mathrm{~cm}$ in height). The individual plastic vials containing the animals were filled with the appropriate volume $(\sim 25 \mathrm{~mL})$ of seafood extract-laced ASW $\left(15^{\circ} \mathrm{C}\right)$ and sealed with screw-top caps. Thus, the animals were isolated from exposure to any secretagogues (pheromones, waste products, etc.) that might have been released by other animals during the training experience.

\section{Procedure}

Food sample and extract preparation. Small $\left(\sim 2 \mathrm{~mm}^{3}\right)$ food pieces used in tests of feeding behavior were prepared fresh, $\sim 1 \mathrm{~h}$ before their use and were covered with ASW. Shrimp and bay scallop extracts were prepared on the day of use as described in Rogers et al. (1996). In brief, $110 \mathrm{mg}$ (Experiment 1) or $110 \mathrm{~g}$ (all the other 
experiments) of shellfish meat was added to $50 \mathrm{~mL}$ of ASW and pureed in a blender. The resulting stock solution (Experiment 1) or paste (all the other experiments) was then frozen and thawed each day to make fresh solutions of the appropriate concentration by dilution with ASW. The final working solutions were filtered to remove large food particles and were kept refrigerated.

Behavioral testing. For each individual animal, bite-strike latencies to pieces of scallop and shrimp were measured, three times each during each test session, in counterbalanced presentation order (scallop, shrimp, shrimp, scallop, shrimp, scallop) with an intertest interval of $2 \mathrm{~min}$. Test sessions were administered prior to conditioning (baseline), $2 \mathrm{~h}$ following the conclusion of each of three consecutive training sessions and $24 \mathrm{~h}$ after the last conditioning trial. An exception occurred in Experiment 1, where because of an oversight, the animals were not tested after the end of the first conditioning session. All the latencies were measured to the nearest second, using a handheld stopwatch, by an observer without knowledge of the specific conditioning history of the foods tested. Following the initial determination of bite-strike latencies to scallop and shrimp, the subjects were assigned to conditioning treatments in such a way that the average response latencies to $\mathrm{CS}+$ and $\mathrm{CS}-$, as well as to scallop and shrimp, were approximately equivalent.

Context conditioning training. On each of three subsequent training days following the initial baseline measurement of bitestrike latencies, the animals received a single 25 -min exposure to shrimp (or scallop) extract, followed $3 \mathrm{~h}$ later by a 25 -min exposure to scallop (shrimp) extract. In Experiment 1, extract concentrations of $2.2 \mathrm{mg} / \mathrm{mL}$ were used for both shrimp and scallop, as originally reported in Rogers et al. (1996). However, in the course of preparing these solutions, it became obvious that they were extremely dilute, much less so than those used in our original discrete-trial procedure (Farley et al., 1990). After checking with Dr. Ron Rogers (1996, personal communication), we determined that the concentration reported in Rogers et al.'s (1996) study had been erroneous. The concentration that had in fact been used was $2.2 \mathrm{~g} / \mathrm{mL}(1,000-$ fold more concentrated). Thus, this concentration was used in all subsequent experiments and is hereafter designated as the standard concentration. This concentration approximates that $(0.45 \mathrm{~g} / \mathrm{mL})$ used in our previous discrete-trial studies of chemosensory conditioning (Farley et al., 1990; Farley et al., 1997), although it was more concentrated by a factor of 4.44 .

One of the extracts was designated $\mathrm{CS}+$. While immersed in $\mathrm{CS}+/ \mathrm{ASW}$, animals received 503 -sec presentations of high-speed (250 rpm, orbital displacement of $\sim 4 \mathrm{~mm}$ ) orbital rotation (shaking) at an interstimulus interval (ISI) of $0.5 \mathrm{~min}$. During exposure to the other nonreinforced food extract (CS-), the animals were placed in the conditioning vials and chamber, but no orbital rotation was given. For half the animals ( $n=5$ for each replication of an experiment), scallop was the CS + and shrimp was the CS - . For the other half $(n=5)$, this assignment was reversed. Conditioning occurred at $16^{\circ} \mathrm{C}$ in the dark, except for the presence of red safety lights that failed to excite the photoreceptors.

The same general discriminative context-conditioning procedure was used in all three experiments, with the exceptions of the differences in feeding schedule and extract concentration described previously. A single replication of Experiment 1 was conducted in September 1996, using 10 animals. Two replications ( $n=10$ each) of Experiment 2 were conducted in November and December 1996, respectively. Two replications ( $n=10$ each) of Experiment 3 were conducted in January and November 1997.

\section{Statistical Analyses}

All the results are presented as mean $\pm S E M$, unless otherwise indicated.

For Experiments 1-3, the following analyses of variance (ANOVAs) were conducted. Because Rogers et al. (1996) analyzed their 24-h retention test data separately from their 2-h postacquisition data, we analyzed our results in the same manner. In our first analysis, the baseline data and the 2-h postacquisition results on Test Days 1-3 were subjected to a three-factor ANOVA with one repeated measure. Factor 1 was the treatment (i.e., reinforced or nonreinforced), Factor 2 was the contextual cue tested (i.e., shrimp or scallop), and Factor 3 was the number of training trials (i.e., 0, 50, 100 , or 150). Data for this ANOVA were combined within each treatment condition (reinforced or nonreinforced) according to the type of stimulus used (i.e., shrimp or scallop) such that each animal contributed a single score to both levels of the treatment. This resulted in 10 observations (i.e., 10 subjects) for each treatment level. In a second analysis, the data were analyzed separately for the treatment conditions in which scallop or shrimp served as the CS+, using an ANOVA in which both test day/training trials (i.e., 0, 50, 100 , or 150 ) and test cue (i.e., CS + vs. CS -) were within-subjects factors. In a third analysis, the 24-h retention interval data were analyzed using a two-factor ANOVA, where Factor 1 was the treatment history and Factor 2 was the contextual cue used, as in Rogers et al. We also compared same-day results for $\mathrm{CS}+$ versus $\mathrm{CS}-$. These comparisons were performed using standard, two-tailed, correlated-sample $t$ tests; significance was set at a confidence level of $95 \%$. Our statements concerning statistical significance apply to both first- and three-trial results, unless indicated otherwise. When a set of tests is reported as significant (nonsignificant), the smallest (largest) obtained $F$ (or $t$ ) statistic for the set is given.

The preceding ANOVAs, in which the acquisition and retention data were analyzed separately, were supplemented by an additional ANOVA for the results of each experiment in which these data were combined. Here, Factor 1 was the conditioning treatment, and Factor 2 was the test day (baseline, multiple acquisition days, or retention). The chemosensory identity of the reinforced versus nonreinforced cue (i.e., whether scallop or shrimp) was ignored. The added $d f \mathrm{~s}$ associated with the error terms from these analyses provided greater power for $F$ ratio significance tests. As was expected, the obtained $F$ values were in general larger than the corresponding values from the earlier ANOVAs. Despite the greater statistical power, however, in no case did an obtained $F$ value from these analyses ever reach significance when the analogous $F$ value from the earlier ANOVAs had failed to. Because none of our conclusions were altered by these reanalyses of the results, and to save space, we will simply summarize these analyses without presenting the associated list of $F$ statistics.

\section{Results and Discussion}

Because Rogers et al. (1996) tested each chemosensory stimulus only once per session, whereas we tested each stimulus three times, we will present the results both for the first test trial to scallop and shrimp (which are directly comparable to Rogers et al., 1996), and for all three presentations.

As was described earlier in the Method section, Experiments 1-3 differed slightly from one another as to (1) the shellfish extract concentration used during training $(2.2 \mathrm{mg} / \mathrm{mL}$ for Experiment 1 vs. $2.2 \mathrm{~g} / \mathrm{mL}$ for Experiments 2 and 3), and (2) feeding schedule (animals received no supplemental feedings once behavioral training had begun in Experiments 1 and 2 vs. feeding $4 \mathrm{~h}$ after each training session in Experiment 3). To anticipate the results, these procedural differences were inconsequential insofar as the principal findings and conclusions were concerned.

\section{Baseline Bite-Strike Latencies: Experiments 1-3}

As was expected, because of the matching method used in assigning subjects to treatment condition, and re- 
gardless of whether the mean or the median was used as an index of central tendency, there were no systematic differences in latencies to shrimp versus scallop, or CS + versus CS - in any experiment. Nor was the interaction between these two factors ever significant. When the results for all three experiments were pooled, the latencies for shrimp, scallop, $\mathrm{CS}+$, and $\mathrm{CS}-($ all $n \mathrm{~s}=50)$ were the following: $4.0 \pm 0.9$ and $4.9 \pm 0.8 \mathrm{sec}$ (first- and three-trial results, respectively); $4.0 \pm 1.3$ and $6.7 \pm$ $1.4 \mathrm{sec} ; 3.7 \pm 1.2$ and $6.7 \pm 1.2 \mathrm{sec}$; and $4.3 \pm 1.0$ and $5.0 \pm 1.2 \mathrm{sec}$.

\section{Experiment 1: Dilute Extracts, No Supplemental Feedings}

Figure 1 depicts the bite-strike latencies to $\mathrm{CS}+$ and $\mathrm{CS}-$ during baseline, 1-2 $\mathrm{h}$ after Conditioning Days 2 and 3, and during the 24-h postconditioning test (Day 4). Figure 1A summarizes the data for the first test trial, whereas Figure 1D summarizes the results for all three trials. In Figures $1 \mathrm{~A}$ and 1D, the data have been presented without regard to whether shrimp or scallop was used as the CS + . Training produced a gradual and cumulative increase in response latencies to both $\mathrm{CS}+$ and CS-. By the time of the 24-h retention test, the response latency changes observed represented two- to fourfold increases relative to baseline. These increases typically were first apparent after the end of the third conditioning session and thus required at least two to three training sessions to develop.

The ANOVAs confirmed these impressions. For the analyses of the latencies during baseline and Test Days 2 and 3, the three-factor ANOVA revealed a main effect of test day $[F \mathrm{~s}(2,16)>4.70, p<.025]$. All other main effects and interactions failed to reach significance $\left[F_{\mathrm{S}}<\right.$ $2.73, p \mathrm{~s}>.10]$. When the data were analyzed separately for the treatment conditions in which scallop or shrimp served as $\mathrm{CS}+$, a similar pattern obtained. When scallop was used as CS+ (Figures 1B and 1E), the main effect of test day was significant for the first-trial data $[F(2,8)=$ $7.52, p<.02]$, but not for the three-trial data $[F(2,8)=$ $2.03, p>.20]$. Similarly, when shrimp was used as CS+ (Figures $1 \mathrm{C}$ and $1 \mathrm{~F}$ ), the main effect of test day was significant for the first-trial data $[F(2,8)=4.14, p<.05]$ but just missed significance for the three-trial data $[F(2,8)=$ $3.60, p<.052]$. Regardless of which cue was used as $\mathrm{CS}+$, neither the main effect of test cue $[F \mathrm{~s}(1,4)<2.04$, $p>.23]$ nor the interaction of test day and test cue $[F \mathrm{~s}(2,8)<3.29, p>.09]$ was significant. Comparisons of $\mathrm{CS}+$ versus CS - on Days 2 and 3 revealed no significant differences for either the first- [all $t \mathrm{~s}(4)<0.98$ ] or the three-trial [all $t \mathrm{~s}(4)<0.30]$ data.

Analyses of the 24-h retention data indicated that neither the main effects of conditioning treatment $[F \mathrm{~s}(1,16)<$ $0.45]$ or contextual cue $\left[F_{\mathrm{s}}(1,16)<2.48, p>.13\right]$ nor the interaction $[F \mathrm{~s}(1,16)<0.24]$ was significant. None of the same-day comparisons of CS + versus $\mathrm{CS}-$ was significant [all $t \mathrm{~s}(4)<1.46, p \mathrm{~s}>.21$ ].

\section{Experiment 2: Standard Concentration of Extracts, No Supplemental Feedings}

Because the results were essentially identical for the two replications of this experiment, their data were combined. Figures 2A (first trial) and 2D (three-trial data) depict the bite-strike latencies to CS + and CS- prior to training, as well as during all subsequent tests, ignoring which chemosensory cue served as $\mathrm{CS}+$. Approximately equivalent response latency increases developed to $\mathrm{CS}+$ and $\mathrm{CS}-$ across training/testing. The threefactor ANOVA of the acquisition data yielded a significant main effect of test day $[F \mathrm{~s}(3,54)>8.53, p<.0001]$. But neither the main effect of conditioning treatment $[F \mathrm{~s}(1,18)<2.76, p>.10]$ nor that of test cue $[F \mathrm{~s}(1,18)<$ $1]$ was significant. None of the two-way $\left[F_{\mathrm{s}}(3,54)<\right.$ $2.10, p>.10]$ or triple $[F \mathrm{~s}(3,54)<1]$ interactions was significant.

When the data for each CS + treatment condition were analyzed separately, a slightly different pattern obtained. The main effect of test day was significant $\left[F_{\mathrm{s}}(3,27)>\right.$ $9.50, p<.0001]$ when scallop was used as the CS+ (Figures 2B and 2E), but not when shrimp was used as the CS+ [Figures 2C and 2F; $F(3,27)<1.68, p>.20$ ]. Regardless of which cue was used as the CS + , neither the main effect of test cue [i.e., CS + vs. CS $-; F \mathrm{~s}(1,9)<$ $1.60, p>.23]$ nor the interaction of test cue and test day $[F \mathrm{~s}(3,27)=1.34, p>.28]$ was significant. None of the comparisons of CS + versus CS - on Test Days 1-3 was significant $[t \mathrm{~s}(9)<1.68, p>.12]$.

For the 24-h retention data, neither the main effects of treatment $\left[F_{\mathrm{s}}(1,36)<1\right]$ and contextual cue $\left[F_{\mathrm{s}}(1,36)<\right.$ $2.40, p>.13]$ nor their interaction $[F \mathrm{~s}(1,36)<1]$ was significant. None of the comparisons of CS + versus $\mathrm{CS}-$ was significant [all $t \mathrm{~s}(9)<1.28, p \mathrm{~s}>.22$ ]

\section{Experiment 3: Standard Concentration of Extracts, Supplemental Feedings}

Because the results were essentially identical for the two replications of this experiment, they were combined. Figures 3A (first trial) and 3D (three-trial data) depict the bite-strike latencies to CS + and CS - prior to training, as well as during all the retention tests, regardless of which cue served to define the context. Approximately equivalent response latency increases to CS + and CS- were observed following the 1st conditioning day. The three-factor ANOVA of the acquisition data (Test Days 1-3) revealed a significant main effect of test day $[F \mathrm{~s}(3,54)>36.39, p<.0001]$. Neither the main effect of conditioning treatment nor that of test cue was significant $[F \mathrm{~s}(1,18)<1]$. The interaction between test cue and test day was significant for the first-trial data $[F(3,54)=3.77$, $p<.05]$, which reflected the longer latencies for Test Days 1 and 4 when shrimp was used as the CS + (Figures $3 \mathrm{C}$ vs. 3B). This interaction was not significant for the three-trial data $[F(3,54)<1$; Figures $3 \mathrm{~F}$ vs. 3E]. Neither the two-way interaction between test day and conditioning treatment $[F \mathrm{~s}(3,54)<1]$ nor that between condi- 

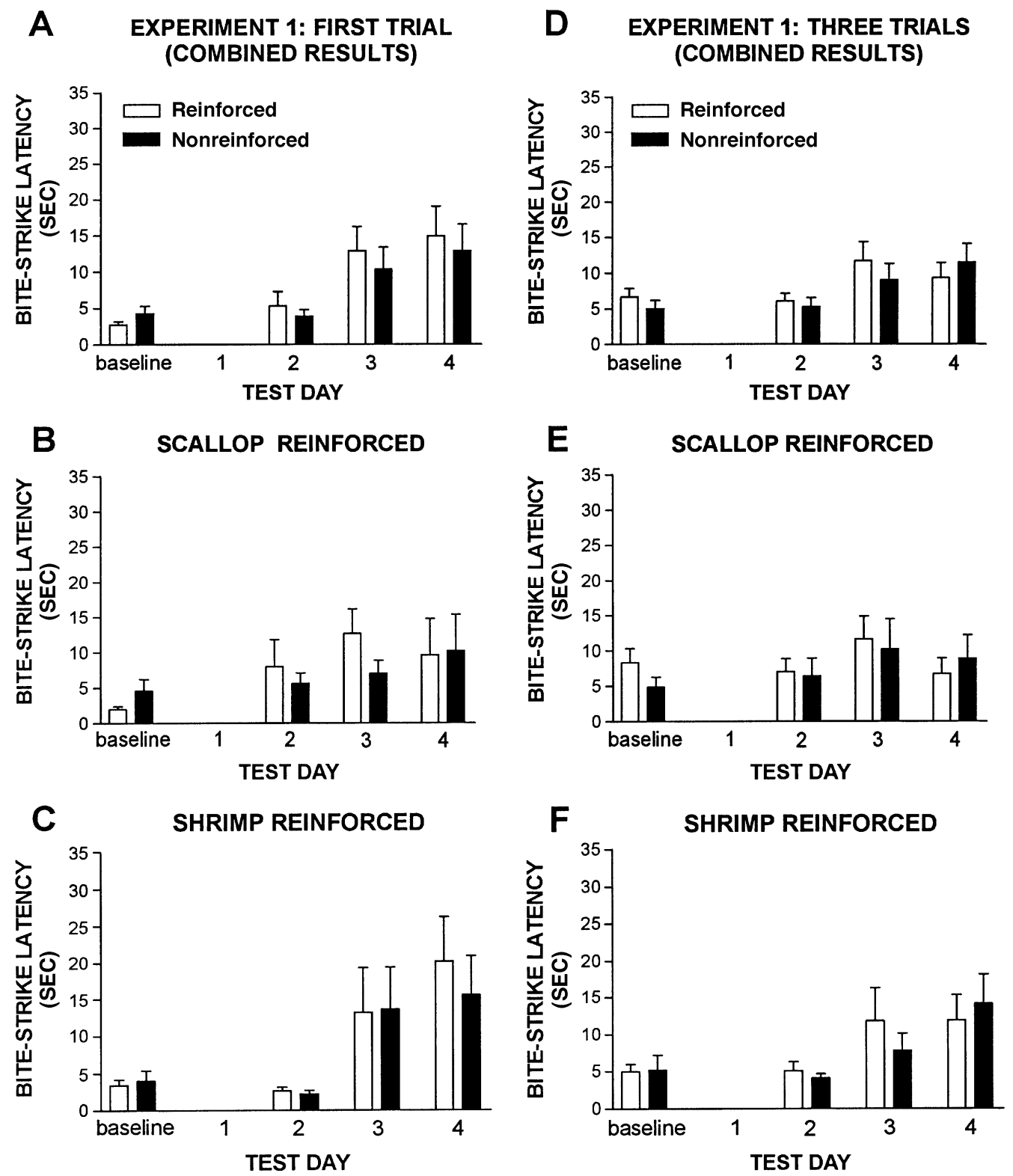

Figure 1. Test results of attempted differential chemosensory contextual conditioning in Experiment 1. Firsttrial results appear on the left $(\mathrm{A}-\mathrm{C})$, and three-trial results appear on the right (D-F). Context-US associations were evaluated using bite-strike latencies. Animals were given 3 successive daily 25-min exposures to both scallop and shrimp extracts, which defined the chemosensory contexts. For each animal, one context was reinforced by orbital rotation/shaking US presentations (reinforced), and the other context was never reinforced (nonreinforced). Panels $A$ and $D$ present the mean latency data (in seconds) for reinforced and nonreinforced contextual cues across training days and at a 24-h retention interval. The data have been combined without regard to which cue served as the reinforced or the nonreinforced context. Due to an oversight, posttraining tests following the first training day were not administered. Panels B,C and E,F display mean acquisition and retention data, with the data separated as to the type of chemosensory contextual cue that was reinforced (i.e., scallop [B,E] or shrimp [C,F]). The final concentrations of the shellfish extracts were $2.2 \mathrm{mg} / \mathrm{mL}$. Error bars indicate standard errors.

tioning treatment and test cue $[F \mathrm{~s}(1,18)<1]$ was significant. The triple interaction also was not significant $\left[F_{\mathrm{S}}(3,54)<1\right]$.

Regardless of whether scallop (Figures 3B and 3E) or shrimp (Figures $3 \mathrm{C}$ and $3 \mathrm{~F}$ ) was used as the $\mathrm{CS}+$, the effect of test day was significant $\left[F_{\mathrm{s}}(3,27)>20.71, p<\right.$
.0001]. Neither the effect of conditioning treatment $\left[F_{\mathbf{S}}(1,9)<1\right]$ nor its interaction with test day $\left[F_{\mathrm{s}}(3,27)<\right.$ 1]. None of the comparisons of CS + versus CS - on Days 1-3 was significant [all $t \mathrm{~s}(9)<0.99, p \mathrm{~s}>.40]$.

Analysis of the 24-h retention interval data indicated that the main effect of conditioning treatment was non- 
A EXPERIMENT 2: FIRST TRIAL
(COMBINED RESULTS)
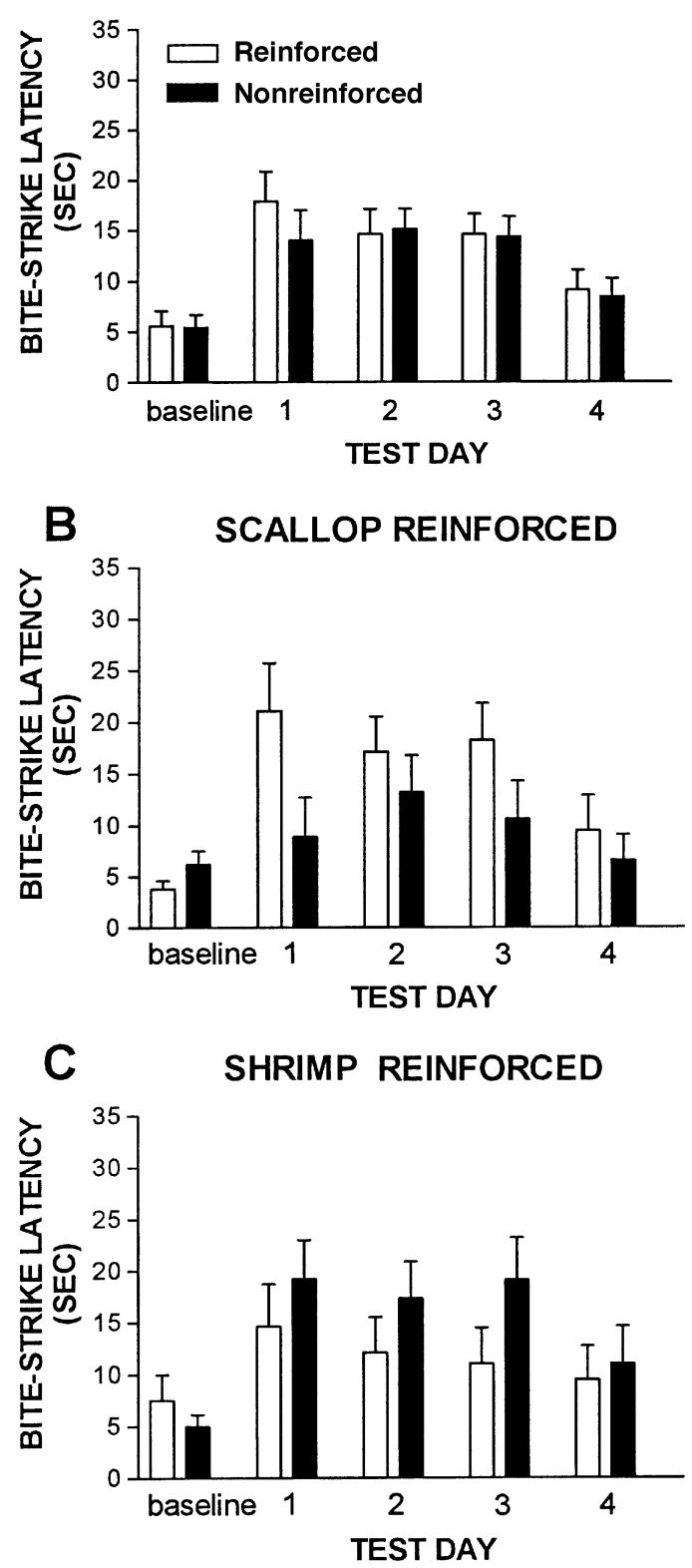

D EXPERIMENT 2: THREE TRIALS (COMBINED RESULTS)
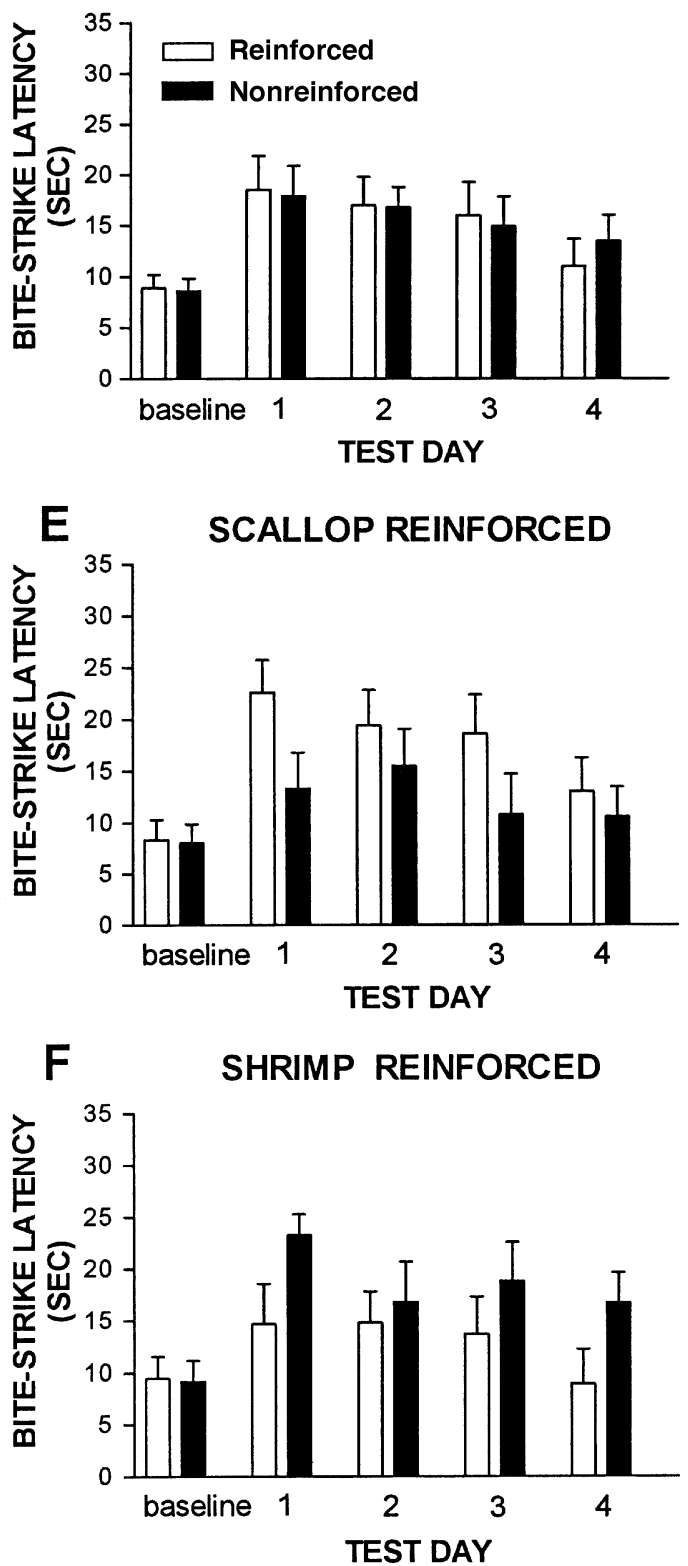

Figure 2. Test results of attempted differential chemosensory contextual conditioning in Experiment 2. Firsttrial results appear on the left $(\mathrm{A}-\mathrm{C})$, and three-trial results appear on the right (D-F). The animals were trained as in Experiment 1, with the exception that the final concentrations of the shellfish extracts were $2.2 \mathrm{~g} / \mathrm{mL}$. Panels $A$ and $D$ present the mean latency data (in seconds) for reinforced and nonreinforced contextual cues across training days and at a 24-h retention interval. The data have been combined without regard as to which cue served as the reinforced or the nonreinforced context. Panels B,C and E,F display mean acquisition and retention data, with the data separated as to the type of chemosensory contextual cue that was reinforced (i.e., scallop [B,E] or shrimp [C,F]). Error bars indicate standard errors.

significant $[F \mathrm{~s}(1,36)<1]$. There was a significant main effect of contextual cue type for the first-trial data $[F(1,36)=8.67, p<.01]$, but not for the three-trial data $[F(1,36)=1]$. The former difference reflects the greater latencies observed when shrimp was used as the CS+, rather than scallop. The interaction between condition- ing treatment and contextual cue was not significant $[F \mathrm{~s}(1,36)<1.96, p>.17]$. None of the four comparisons of CS + versus CS - was significant either [all $t \mathrm{~s}(9)<1.48, p \mathrm{~s}>.15]$.

Reanalysis of results, using ANOVAs with greater statistical power. Reanalysis of both first- and three-trial 
data for Experiments 1-3 when acquisition and retention results were combined (see the Statistical Analysis section) failed to yield any additional significant $F$ ratio values not already revealed by the principal ANOVAs.

\section{Contextual Conditioning Failed to Decrease Bite- Strike Latencies to CS + or to Differentially Affect CS + Versus CS - Latencies}

The general pattern of results obtained in Experiments 1-3 can be summarized very simply. Contextual chemosensory conditioning resulted in large, approximately equivalent increases in bite-strike latencies to the $\mathrm{CS}+$ and the CS - across acquisition (training) days. In contrast to Rogers et al. (1996), who reported small ( $\sim 0.5$-sec) decreases in bite-strike latencies to the CS + and small $(\sim 1.0-$ to $1.5-\mathrm{sec}$ ) increases to the $\mathrm{CS}-$ following the 3rd day of training, we observed large $(>5-\mathrm{sec})$ increases in response latencies to both the $\mathrm{CS}+$ and the $\mathrm{CS}-$. These increases persisted during the 24-h retention test as well. The lack of stimulus specificity in the present experiments was pronounced. When the results from all three experiments are considered collectively, Figures 1-3 contain 66 opportunities for posttraining isochronal comparison of latencies to the CS + and the CS- . At no time was there a significant difference in latencies to the $\mathrm{CS}+$ versus the $\mathrm{CS}-$.

A comparison of the results for Experiment 1 versus Experiments 2 and 3 suggests that the latency increases developed more quickly in the latter experiments, in which more concentrated extract solutions were used. For example, the latencies observed after 2 days of training in Experiment 1 (Figures 1A and 1D) were, on average, not significantly longer than baseline; a 3rd day of training was required before significant differences emerged. In contrast, the latencies in Experiments 2 and 3 significantly exceeded baseline values after just a single conditioning session (Figures 2A and 2D and Figures 3A and 3D) and failed to change much with additional training. There was also a suggestive trend for the response latency increases to be greater for the more concentrated solutions by the end of training: $150 \%-300 \%$ increases for Experiments 2 and 3 versus $100 \%-150 \%$ increases for Experiment 1 .

The equivalent increases in response latencies to both the $\mathrm{CS}+$ and the $\mathrm{CS}-$ in Experiments 1-3 indicates that temporal overlap of the CS and the US was not essential for the latency increases observed to the food samples. This pattern is reminiscent of that observed for control groups in our earlier discrete-trial study (Farley et al., 1990, Figure 8). There, animals that had received repeated exposures to a shellfish extract, but no rotational USs (i.e., a CS-alone treatment), showed bite-strike latency increases to a relatively novel (i.e., nonexposed) shellfish CS that were equivalent to those shown to the exposed but nonreinforced CS. Similar nonselective increases to exposed and nonexposed shellfish CSs were also observed for animals that had experienced explicitly unpaired CS-US presentations (Farley et al., 1990, Fig- ures 5 and 8). In contrast, animals exposed to US-alone presentations exhibited only small increases in latencies to the two (nonexposed) foods tested (Farley et al., 1990, Figure 8), indicating that the latency increases produced by the explicitly unpaired treatment were due to the exposure to the CS. It is worth emphasizing that the latency increases to the exposed CS for the CS-alone and unpaired CS-US control groups of Farley et al. (1990) were significantly smaller than those to the CS+ for animals that experienced CS-US pairings. Moreover, the latter animals exhibited significantly greater increases to the CS + than to a novel (nonexposed) CS, thereby demonstrating the occurrence of associative learning. Nevertheless, the control groups' behavior indicated that a potent nonassociative factor leading to CS+ latency increases for Hermissenda was mere repeated exposure to shellfish extracts.

\section{EXPERIMENT 4}

The lack of CS specificity for the results in Experiments 1-3 raises the question of whether the USs delivered during Experiments 1-3 were at all critical for the increased latencies observed to the CS+ and the CS-. Thus, in Experiment 4 , we exposed animals to the same general training procedure and shellfish extracts as those in Experiments 1-3 but simply omitted all US presentations.

\section{Method}

\section{Subjects}

A total of 10 animals was used. All the animals received supplemental feedings at the end of each training day. A single replication was conducted in October 1998.

\section{Apparatus}

The apparatus was the same as those in the previous experiments.

\section{Procedures}

The same general procedure as that in Experiments 1-3 were used, with the following exceptions. On each of three successive training days, the animals were placed in plastic vials in the top of the orbital shaker and exposed for $25 \mathrm{~min}$ to the standard shellfish extract concentration $(2.2 \mathrm{~g} / \mathrm{mL})$. For half the animals $(n=5)$, this cue was scallop; for the other 5 animals, this cue was shrimp. Following exposure to the first cue, the animals were returned to their home aquaria for $3 \mathrm{~h}$. They were then placed within ASW-filled vials in the top of the orbital shaker for another 25 -min period. No rotational USs were ever given. Thus, the animals in Experiment 4 received three prolonged exposures to a single shellfish extract (rather than two different ones, as in Experiments 1-3), but no orbital rotation USs. The animals were trained in the presence of a red safety light at $\sim 16^{\circ} \mathrm{C}$. Tests of bite-strike behavior to both scallop and shrimp were conducted as in Experiments 1-3.

\section{Results and Discussion}

Baseline response latencies to shrimp and scallop failed to differ from one another, regardless of whether the results from just the first (Figures 4A-4C) or from all three trials (Figures 4D-4F) were considered. There were no systematic differences in latencies to shrimp $(2.2 \pm 0.3$ and $3.7 \pm$ 
$0.5 \mathrm{sec}$ for first- and three-trial data, respectively) versus scallop $(1.7 \pm 0.3$ and $2.7 \pm 0.3 \mathrm{sec})$ or for the subsequently exposed $(1.8 \pm 0.3$ and $3.3 \pm 0.5 \mathrm{sec})$ versus nonexposed $(2.1 \pm 0.3$ and $3.2 \pm 0.4 \mathrm{sec})$ chemosensory cues.

Figures 4A (first-trial data) and 4D (three-trial data) depict the bite-strike latencies to the exposed and nonexposed cues during baseline, as well as following all exposure sessions, regardless of which stimulus served to define the context. Response latency increases occurred to both cues. The three-factor ANOVA of the acquisition data (Days $1-3)$ revealed a significant effect of test day $\left[F_{\mathrm{S}}(3,24)>\right.$ $11.28, p<.0001]$. The effect of treatment (exposure vs. nonexposure) was not significant $[F \mathrm{~s}(1,8)<1.04]$. However, there was a significant effect of cue type [shrimp vs. scallop; $F \mathrm{~s}(1,8)>10.23, p<.01]$. In general, latencies were longer for animals exposed to shrimp (Figures $4 \mathrm{~B}$ and $4 \mathrm{E}$ vs. Figures $4 \mathrm{C}$ and $4 \mathrm{~F}$ ). The two-way interactions between test cue and training condition were significant $[F \mathrm{~s}(1,8)>5.21, p<.05]$, as was the interaction between test day and test cue for first-trial result $[F(3,24)=4.91$, $p<.008]$, but not for three-trial results $[F(3,24)<1]$. The triple interaction was also significant $\left[F_{\mathrm{s}}(3,24)>3.24\right.$, $p<.04]$. Collectively, these interactions indicated that (1) when the animals were exposed to shrimp, the latency increases to shrimp were smaller than those to scallop (Figures $4 \mathrm{C}$ and $4 \mathrm{~F}$ ) and (2) the magnitude of the differences between exposed and nonexposed cues varied with both training day and exposure cue.

When the data for the two exposure conditions were analyzed separately, the results were as follows. With scallop as the exposed cue (Figures 4B and 4E), the main effect of test day was significant $[F \mathrm{~s}(3,12)>5.76, p<$ $.02]$. The main effect of treatment history was significant for the three-trial data $[F(1,4)=16.50, p<.02]$, but not for the first-trial data $[F(1,4)=5.06, p>.08]$. The interaction of treatment and test day was nonsignificant $\left[F_{\mathrm{s}}(3,12)<2.35, p>.12\right]$. The latencies to the exposed cue (scallop) were not significantly longer than those to the nonexposed cue [shrimp; ts $(4)<2.49, p>$ .06].

When shrimp was the exposed cue (Figures $4 \mathrm{C}$ and $4 \mathrm{~F})$, the main effects of test day $[F \mathrm{~s}(3,12)>6.79, p<$ $.006]$ and treatment history $\left[F_{\mathrm{s}}(1,4)>11.15, p<.03\right]$ were significant. Their interaction was significant for the first-trial data $[F(3,12)=6.98, p<.006]$, but not for the three-trial data $[F(3,12)=1.64, p>.23]$. Comparisons of exposed versus nonexposed cues on Days 1-3 (Figures 4C and 4F) were significant for the first-trial data on Days 2 and $3[t(4)>3.62, p<.05]$, but not on Day $1[t(4)=2.21, p>.09]$. For the three-trial data, the differences were significant on Day $2[t(4)=2.83, p<$ $.05]$, but not on Days 1 and 3 [ts $(4)<2.69, p>.06$ ]

An analysis of the 24-h retention interval data indicated that neither the main effect of treatment $\left[F_{\mathrm{s}}(1,16)<1\right]$ nor that of cue type $[F \mathrm{~s}(1,16)<1]$ was significant. However, their interaction was significant $[F \mathrm{~s}(1,16)>4.89, p<$ $.05]$. The latencies to shrimp were greater than those to scallop for the animals exposed to scallop for the first-trial data $[t(4)=3.39, p<.03]$, but not for the three-trial data $[t(4)<2.05, p>.10]$. The same pattern was obtained for the animals exposed to shrimp [first-trial data, $t(4)=3.91$, $p<.02$; three-trial results, $t(4)<1.52, p>.20$ ].

Reanalysis of both the first- and the three-trial data when acquisition and retention results were combined (providing for greater statistical power in the $F$ tests) failed to yield any additional significant $F$ statistics not already revealed by the principal ANOVAs.

\section{Mere Exposure to a Contextual Chemosensory Stimulus Increases Bite-Strike Latencies; US Presentations Are Not Required}

Exposure to a concentrated shellfish extract increased bite-strike latencies to the food from which that extract had been prepared, as well as to a second food extract with which the animals had no experience. A complicated interaction between exposure condition and test cue occurred such that exposure to shrimp produced larger latency increases to (nonexposed) scallop than to shrimp, whereas exposure to scallop produced larger increases to scallop than to (nonexposed) shrimp. We could think of no simple reason for this particular pattern, and it may reflect a sampling artifact.

A comparison of the results following each exposure session in the present experiment (Figures 4A and 4D) with those obtained following each conditioning session in Experiments 2 (Figures 2A and 2D) and 3 (Figures 3A and 3D) is instructive. In all the experiments, the latencies appeared to reach a similar asymptote $(\sim 15-20 \mathrm{sec})$ following the first training session. Little additional increase was observed after Sessions 2 and 3. This pattern suggests that the major factor responsible for the latency increases to the CS + and the CS - in the earlier experiments of this series was mere exposure to the extracts. Concomitant experience with orbital rotation (shaking) appears to have contributed little.

\section{EXPERIMENT 5}

The previous four experiments failed to provide any evidence for selective changes in response latencies to CS + and CS - , as reported by Rogers et al. (1996), despite our use of very similar training and testing procedures. Given such a discrepant outcome, it is only natural to wonder if the animal populations might have differed.

The animal supplier and general conditions of collection of Hermissenda for both Rogers et al.'s (1996) and our own studies were the same. But because Hermissenda collected from the Monterey Bay region of California are collected from subannual wild populations, unknown genetic and/or local environmental differences among populations might produce different behavioral outcomes despite the use of similar apparatus, training, and testing procedures. In principle, it is possible that the population(s) sampled by Rogers et al. prior to late 1996 were different from ours (sampled November 1996October 1998) in some critical but unknown way that af- 
fected either their capacity to form associations between food extracts and a rotational US or how such associations were expressed. One strategy for assessing these possibilities would be to compare the associative learning for the populations of animals that we sampled here with the performance of 1996 and earlier animals, using the original discrete-trial chemosensory conditioning procedure (Farley et al., 1990).

Thus, we attempted to repeat our findings of stimulusspecific increases in bite-strike latencies to shellfish whose extract had been paired with unidirectional turntable rotation (Farley et al., 1990; Farley et al., 1997). The animals used in this experiment were from the same populations as those that had failed to show contextual conditioning in Experiments 2 and 3 of this series.

Because we were curious about the relative effectiveness of unidirectional turntable-produced versus orbital shaking-produced stimulation as a US, we also included an explicit comparison of these two USs. Orbital rotation (shaking) generally dislodges animals from their substrates (Alkon, 1974; Figure 3 of Rogers et al., 1996). Consequently, animals receive considerable mechanosensory stimulation (e.g., they get tossed and banged around). The turbulence and vestibular stimulation that they receive is also qualitatively different from that produced by unidirectional turntable rotation. Because our discrete-trial studies have used the unidirectional turntable US, whereas contextual-conditioning studies have used orbital rotation/shaking, some of the differences in outcome might conceivably have arisen from this factor. Thus, we also asked whether pairing- and stimulus-specific increases in bite-strike latencies to a food extract CS + could be produced by discrete-trial pairings of CS + and orbital shaker rotation and examined the comparability of any changes observed to those produced by discrete-trial training using unidirectional turntable rotation as the US.

\section{Method}

Subjects

Twenty adult animals, maintained as in the previous experiments, were used.

\section{Apparatus and Procedure}

Unidirectional turntable training. The apparatus and procedures used here were the same as those used previously (Farley et al., 1990; Farley \& Jin, 1997; Farley et al., 1997). One exception was the inclusion of CS + and nonexposed stimulus (NS) test trials $2 \mathrm{~h}$ following each acquisition session in the present experiment. Each animal was placed in a flow-through plastic vial mounted within a rubber stopper, in a $250-\mathrm{mL}$ Ehrlenmayer flask filled with refrigerated standard ASW or ASW laced with an extract of either shrimp or scallop (final concentration: $2.2 \mathrm{~g} / \mathrm{mL}$ ). Five of these flasks were securely attached to the surface of a turntable $(\sim 14 \mathrm{~cm}$ from the center of rotation), which was placed inside a dark refrigerator $\left(16^{\circ}-17^{\circ} \mathrm{C}\right)$. When rotated at $99 \mathrm{rpm}$, the resulting centrifugal force vector was $2.2 \mathrm{~g}$.

The testing and training procedures were essentially the same as those described in Farley et al. (1990; Farley et al., 1997). Following initial tests of feeding reflexes, the animals $(n=10)$ were exposed to 30 pairings of the standard concentration of food extract with turntable rotation on each of three consecutive training days, for a total of 90 trials. For half the animals, scallop was used as the CS+.
For the other half, shrimp was used as the CS + . Each pairing trial lasted $\sim 30 \mathrm{sec}$. The average intertrial interval (ITI) was $4.0 \mathrm{~min}$ (range, 1.5-6.0 $\mathrm{min}$ ). At the onset of each pairing trial, each flowthrough vial containing an animal was placed in a turntable-mounted Ehrlenmayer flask filled with the CS+/ASW. The turntable was then turned on for $30 \mathrm{sec}$. At the end of each trial (cessation of rotation), each flow-through vial containing an animal was removed from the turntable to a 10-gallon rinse tank containing refrigerated standard ASW. The animals remained in the dark throughout training. The ASW in the rinse tank was exchanged after Trials 10 and 20.

Orbital shaker training. The general training procedures used were nearly identical to those described above. The chief difference was the use of brief orbital shaking as the US. On each of three consecutive training days, the animals $(n=10)$ were exposed to 30 paired presentations of a CS + and orbital shaker rotation. Each conditioning trial consisted of a 30-sec exposure to food-extract-laced ASW, the last $3 \mathrm{sec}$ of which overlapped with $3 \mathrm{sec}$ of orbital shaking. A trial began with the placement of the animals into the sealed vials filled with extract-laced ASW (as described in Experiments 1-4), followed by placement of these vials into the top chamber of the orbital shaker apparatus. At the beginning of each ITI ( $8 \mathrm{~min})$, the sealed vials were removed from the orbital shaker. The animals were then removed from the vials and rinsed in ASW. The animals were then placed within the 10-gallon ASW rinse tanks until the next trial began.

\section{Results and Discussion}

Baseline response latencies to shrimp and scallop failed to differ from one another, regardless of whether the results from just the first trial (Figures $5 \mathrm{~A}-5 \mathrm{C}$ and $6 \mathrm{~A}-6 \mathrm{C}$ ) or from all three trials (Figures 5D-5F and 6D-6F) were considered. There were no systematic differences in latencies to shrimp $(3.4 \pm 0.3$ and $5.1 \pm 0.35 \mathrm{sec}$; first- and threetrial data) versus scallop $(2.7 \pm 0.4$ and $5.4 \pm 0.4 \mathrm{sec})$ or to the $\mathrm{CS}+(3.4 \pm 0.33$ and $5.3 \pm 0.41 \mathrm{sec})$ versus the NS chemosensory cue $(3.6 \pm 0.40$ and $5.1 \pm 0.19 \mathrm{sec})$.

\section{Unidirectional Turntable Rotation as a US}

Figures 5A (first trial) and 5D (three-trial data) summarize the outcome of discrete-trial chemosensory conditioning when unidirectional turntable rotation was used as the US. The results agreed well with those reported previously (Farley et al., 1990; Farley et al., 1997). Although response latency increases to both CS + and NS occurred, the changes were substantially greater for the CS+.

The three-factor ANOVA of the acquisition data (Days 1-3) supported this conclusion. The main effects of test day $[F \mathrm{~s}(3,24)>31.86, p<.0001]$ and conditioning treatment $[\mathrm{CS}+$ vs. CS $-; F \mathrm{~s}(1,8)>110.77, p<.0001]$ were significant. The main effect of training cue type (shrimp vs. scallop) was significant for the first-trial data $[F(1,8)=10.56, p<.02]$, but not for the three-trial data $[F(1,8)<1]$. The two-way conditioning treatment $\times$ training cue $\left[F_{\mathrm{s}}(1,8)>7.39, p<.05\right]$ and conditioning treatment $\times$ test day $[F \mathrm{~s}(3,24)>19.13, p \mathrm{~s}<.0001]$ interactions were significant. The two-way test day $\times$ training cue interaction was significant for the first-trial data $[F(3,24)=4.12, p<.02]$, but not for the three-trial data $[F(3,24)=1.22$, n.s. $]$. The triple interaction was also significant $\left[F_{\mathrm{s}}(3,24)>5.28, p<.01\right]$. Latencies to the $\mathrm{CS}+$ were significantly longer than those to the NS on Test Days $1-3$ [all $t \mathrm{~s}(9)>7.02, p<.001]$. 
A EXPERIMENT 3: FIRST TRIAL (COMBINED RESULTS)

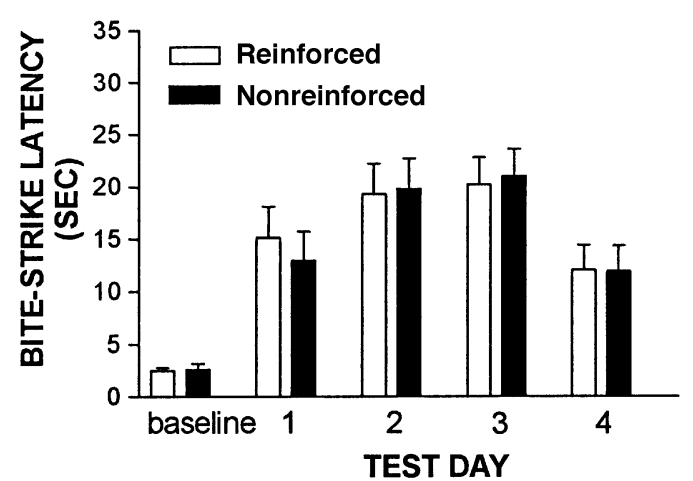

B

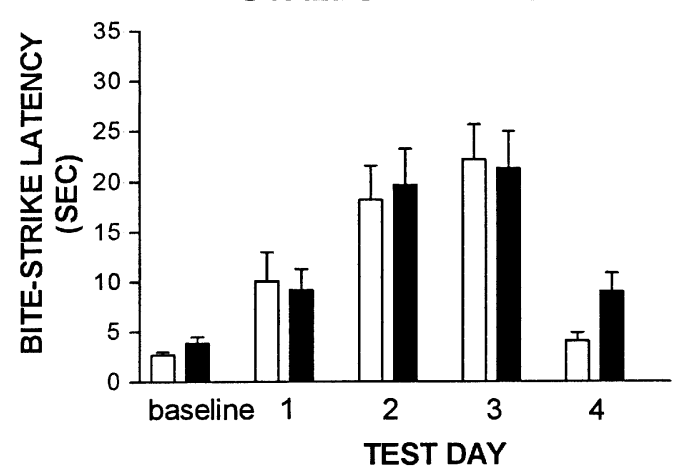

C

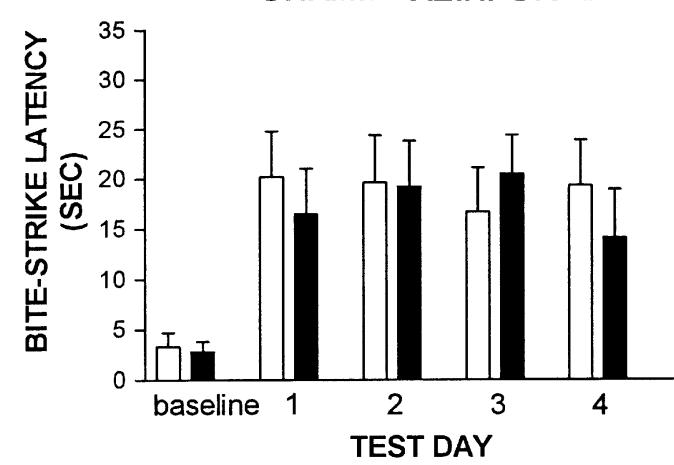

D EXPERIMENT 3: THREE TRIALS (COMBINED RESULTS)

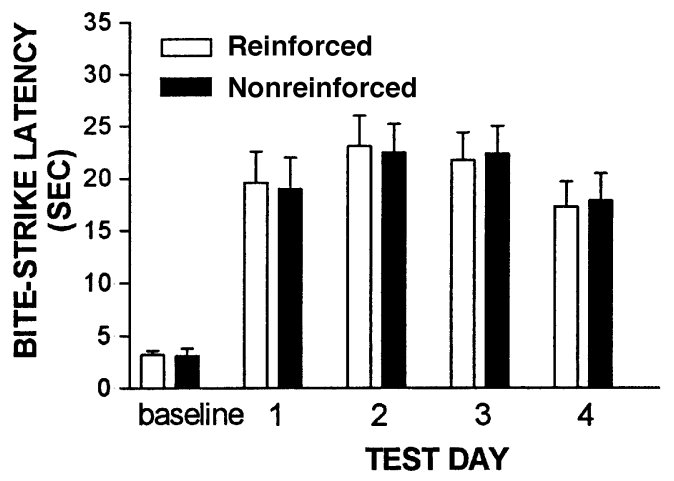

E SCALLOP REINFORCED

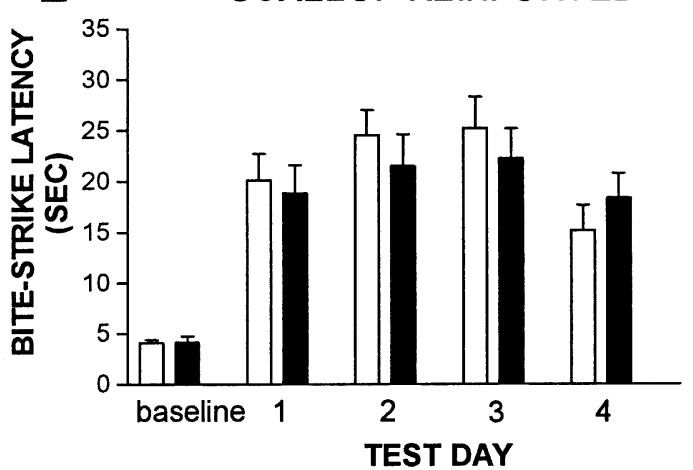

$\mathbf{F}$

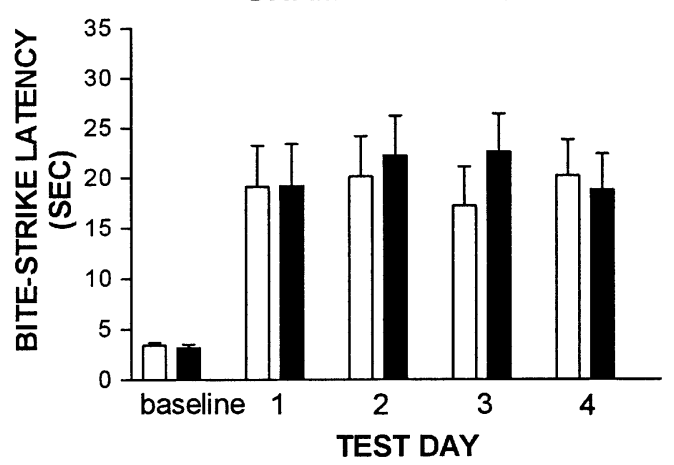

Figure 3. Test results of attempted differential chemosensory contextual conditioning in Experiment 3. Firsttrial results appear on the left $(\mathrm{A}-\mathrm{C})$, and three-trial results appear on the right $(\mathrm{D}-\mathrm{F})$. The animals were trained as in Experiment 1, with the exception that the final concentrations of the shellfish extracts were $2.2 \mathrm{~g} / \mathrm{mL}$ and the animals received supplementary feedings (see the text for additional details). Panels $A$ and $D$ present the mean latency data (in seconds) for reinforced and nonreinforced contextual cues across training days and at a 24-h retention interval. The data have been combined without regard as to which cue served as the reinforced or the nonreinforced context. Panels $B, C$ and E,F display mean acquisition and retention data, with the data separated as to the type of chemosensory contextual cue that was reinforced (i.e., scallop $[\mathrm{B}, \mathrm{E}]$ or shrimp $[\mathrm{C}, \mathrm{F}])$. Error bars indicate standard errors.

Separate analyses of the scallop and shrimp CS1 treatment conditions reinforced the above conclusions. Regardless of whether scallop (Figures 5B and 5E) or shrimp (Figures $5 \mathrm{C}$ and $5 \mathrm{~F}$ ) was used as the $\mathrm{CS}+$, the effects of test day $[F \mathrm{~s}(3,12)>11.20, p<.001]$ and conditioning treatment $\left[F_{\mathrm{s}}(1,8)>46.80, p<.005\right]$ were significant, as was their interaction $\left[F_{\mathrm{s}}(3,12)>8.50, p<.005\right]$. Latencies were significantly longer to the CS + versus the NS on Test Days 1-3 [all $t \mathrm{~s}(4)>3.50, p<.025$ ].

An analysis of the 24-h data indicated a significant effect of treatment $[F \mathrm{~s}(1,8)>22.83, p<.001]$. The effect of training cue was also significant for the first-trial 


\section{A EXPERIMENT 4: FIRST TRIAL (COMBINED RESULTS)}

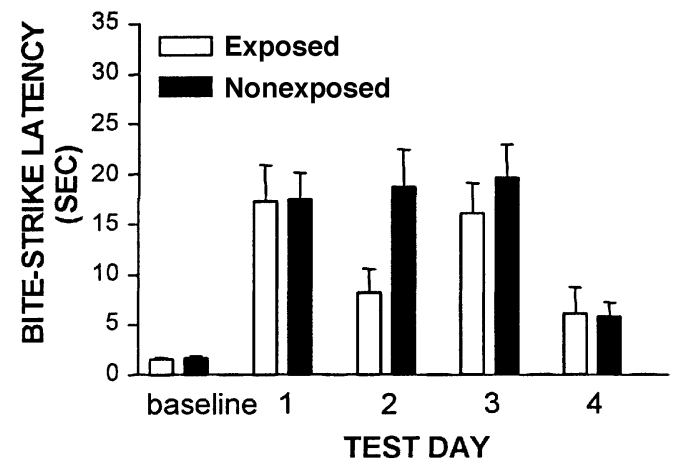

\section{B}

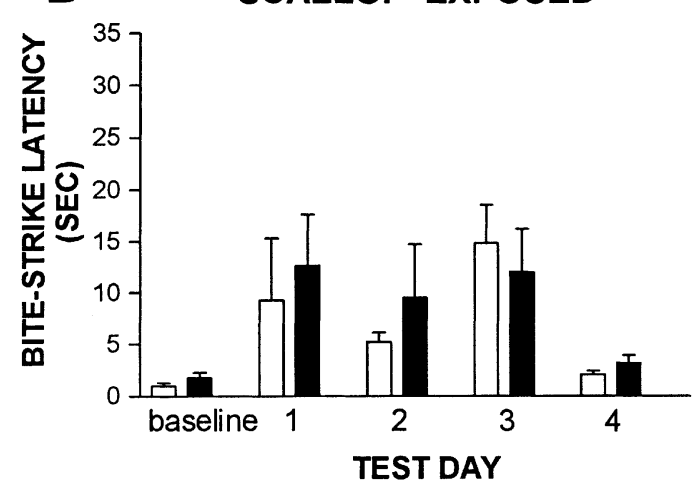

C

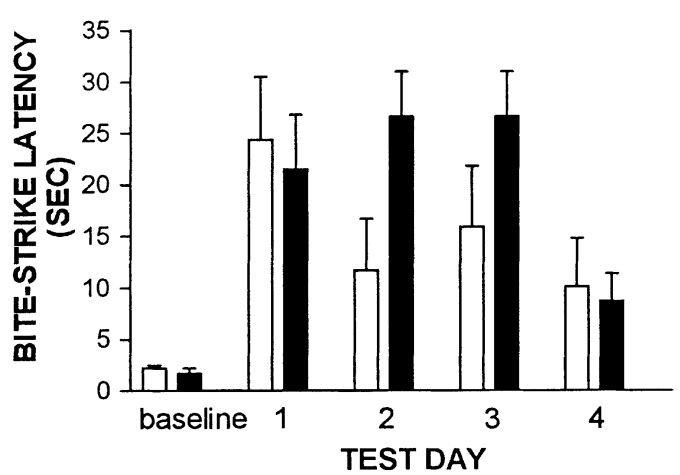

EXPERIMENT 4:THREE TRIALS (COMBINED RESULTS)

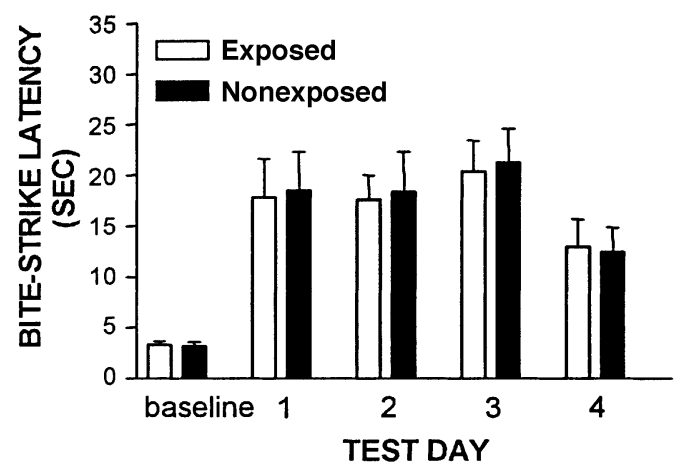

$E$ SCALLOP EXPOSED

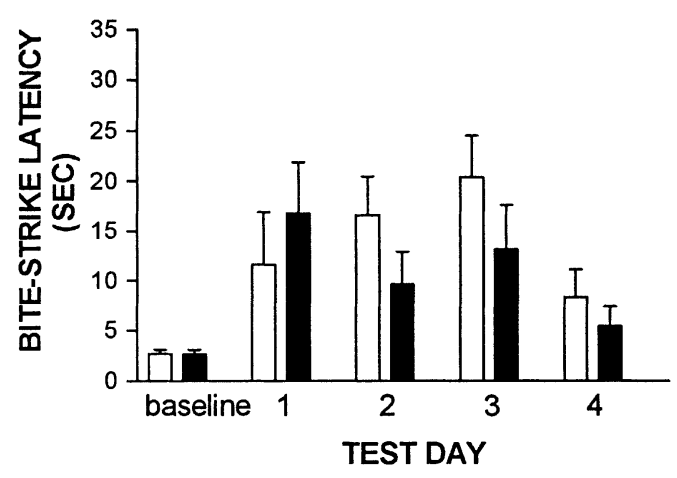

$\mathbf{F}$

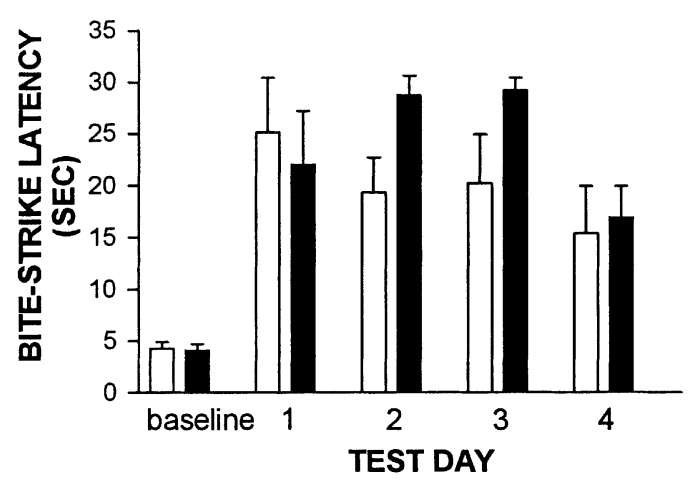

Figure 4. Test results of differential chemosensory context exposure in Experiment 4. The animals were given three successive daily 25-min exposures to a single chemosensory extract and artificial seawater. First-trial results appear on the left (A-C), and three-trial results appear on the right (D-F). No US presentations were administered at any time. The final concentrations of the shellfish extracts were $2.2 \mathrm{~g} / \mathrm{mL}$. Panels $A$ and $D$ present the mean latency data (in seconds) for exposed and nonexposed contextual cues across training days and at a 24-h retention interval. The data have been combined without regard as to which cue animals were exposed to. Panels $B, C$ and $E, F$ display mean acquisition and retention data, with the data separated as to the type of chemosensory contextual cue that animals were exposed to (i.e., scallop $[B, E]$ or shrimp $[C, F]$ ). Error bars indicate standard errors.

$[F(1,8)=12.03, p<.01]$, but not for the three-trial data $[F(1,8)<1]$. The interaction of these factors was not significant $[F(1,8)<1.82]$. Latencies were longer to the $\mathrm{CS}+$ versus the NS at the 24 -h interval $[t \mathrm{~s}(9)>7.74$, $p<.001]$.

\section{Orbital Rotation as a US}

Figures 6A (first-trial data) and 6D (three-trial data) summarize the results of the discrete-trial chemosensory conditioning experiment in which orbital rotation (shaking) was used as the US. Response latencies increased to 


\section{A}

EXPERIMENT 5A: FIRST TRIAL (COMBINED RESULTS)

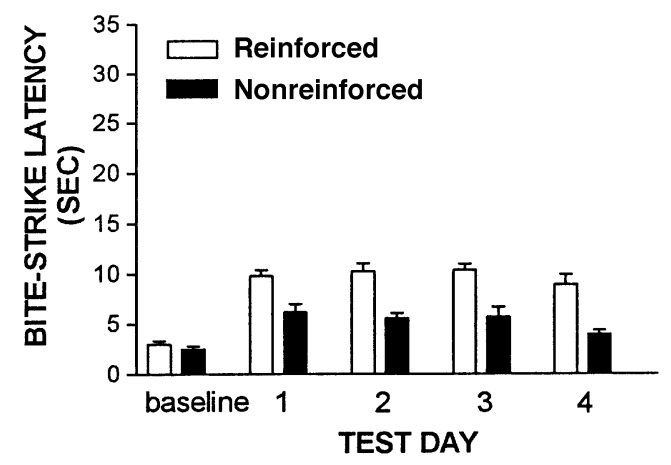

B SCALLOP REINFORCED
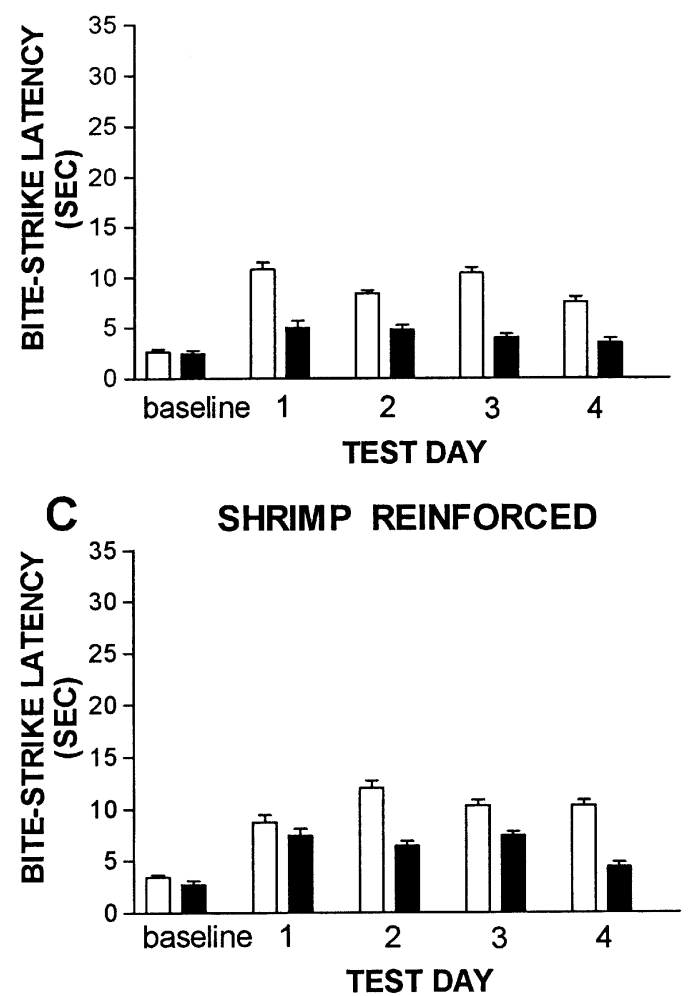
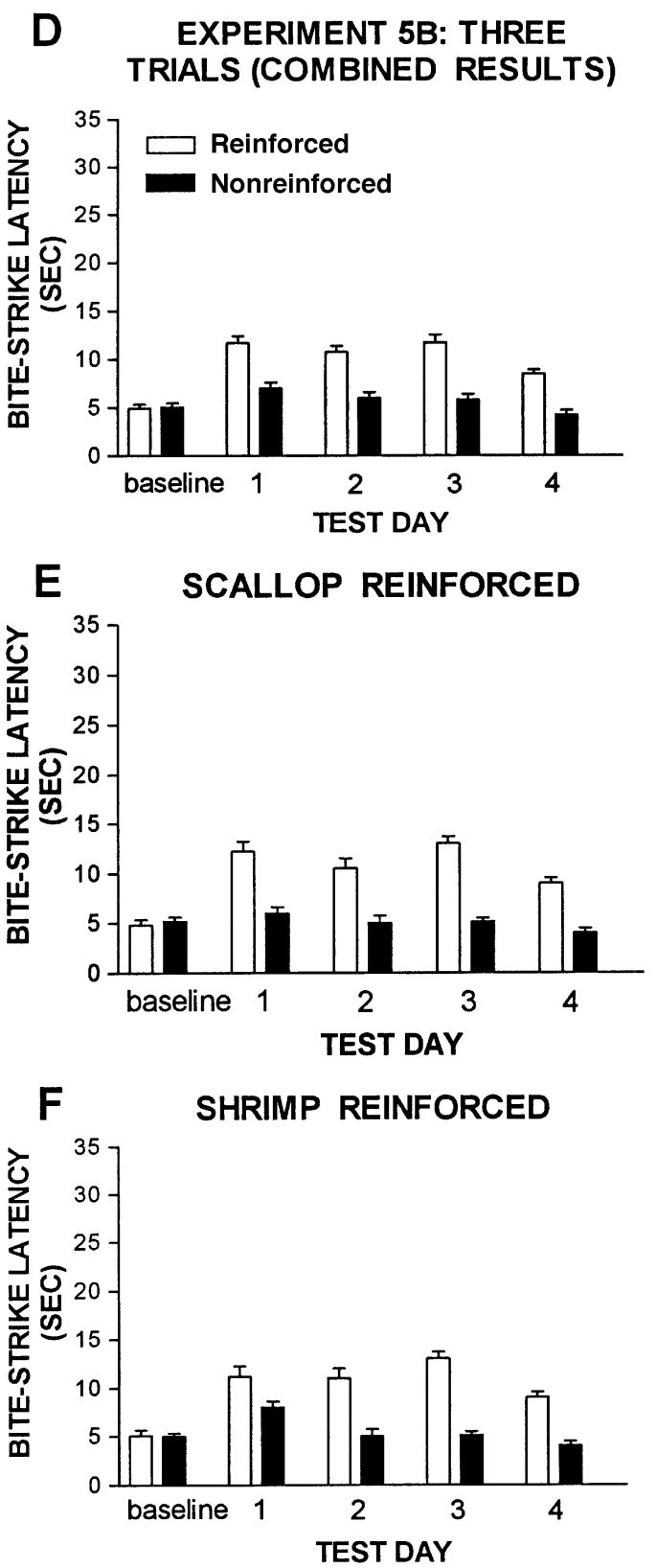

Figure 5. Test results of discrete-trial chemosensory conditioning in Experiment 5A. The animals were given three successive daily training sessions. During each session, the animals received 30 discrete-trial presentations of a chemosensory extract (CS+) paired with high-speed unidirectional turntable rotation (US). The final concentrations of the shellfish extracts were $2.2 \mathrm{~g} / \mathrm{mL}$. The animals were also tested with a second shellfish extract that they had not been exposed to during training sessions. First-trial results appear on the left (A-C), and threetrial results appear on the right (D-F). Panels $A$ and $D$ present the mean latency data (in seconds) for reinforced and nonreinforced chemosensory cues across training days and at a 24-h retention interval. The data have been combined without regard as to which cue served as the reinforced or the nonreinforced context. Panels B,C and E,F display mean acquisition and retention data, with the data separated as to the type of chemosensory cue that was reinforced (i.e., scallop [B,E] or shrimp [C,F]). Error bars indicate standard errors.

both the CS + and the NS across conditioning days, but the changes were greater for the CS+.

The three-factor ANOVA of the acquisition data (Days $1-3)$ revealed significant effects of test day $\left[F_{\mathrm{s}}(3,24)>\right.$ $38.69, p<.0001]$ and conditioning treatment $[\mathrm{CS}+\mathrm{vs}$.
$\left.\mathrm{CS}-; F_{\mathrm{s}}(1,8)>130.05, p<.0001\right]$. The effect of training cue type (shrimp vs. scallop) was not significant $[F \mathrm{~s}(1,8)<1]$. For the first-trial results $[F(1,8)=36.29$, $p<.0001]$, but not for the three-trial results $[F(1,8)<1]$, the test cue $\times$ training cue interaction was significant. 
The test day $\times$ test cue interaction was significant $\left[F_{\mathrm{s}}(3,24)>15.26, p<.0001\right]$. The test day $\times$ training cue interaction was significant for the first-trial data $[F(3,24)=5.27, p<.01]$, but not for the three-trial data $[F(3,24)<1]$. The triple interaction was not significant $\left[F_{\mathrm{s}}(3,24)<1\right]$. Latencies to the $\mathrm{CS}+$ were significantly longer than those to the NS on Test Days 1-3 [all $t \mathrm{~s}(9)>$ $6.52, p<.01]$.

When the data were analyzed separately for the scallop and the shrimp treatment conditions, the results were as follows. Regardless of whether scallop (Figures 6B and $6 \mathrm{E}$ ) or shrimp (Figures $6 \mathrm{C}$ and $6 \mathrm{~F}$ ) was paired with shaking, the effects of test day $[F \mathrm{~s}(3,12)>11.90, p<.001]$ and conditioning treatment $\left[F_{\mathrm{s}}(1,4)>17.78, p<.01\right]$ were significant, as was their interaction $[F \mathrm{~s}(3,12)>6.08$, $p<.01]$. Comparisons of the CS + versus the NS on Test Days 1-3 for the animals conditioned to scallop (Figures $6 \mathrm{~B}$ and $6 \mathrm{E}$ ) were significant [all $t \mathrm{~s}(4)>3.26, p<.05$ ]. For the animals conditioned to shrimp, comparisons of the $\mathrm{CS}+$ versus the NS each on test day (Figure 6B) indicated significantly longer latencies for the CS + on Days 1 and 2 for the first-trial data $[t \mathrm{~s}(4)>2.99, p<.05]$ and for all 3 days for the three-trial data [Figure $6 \mathrm{E} ; t \mathrm{~s}(4)>4.31, p<$ .02].

Analysis of the 24-h data indicated a significant effect of treatment $\left[F_{\mathrm{S}}(1,8)>22.83, p<.001\right]$. The effect of training cue was also significant for the first-trial results $[F(1,8)=5.47, p<.05]$, but not for the three-trial results $[F(1,8)<1]$. The interaction was significant for the first-trial results $[F(1,8)=21.48, p<.002]$, but not for the three-trial results $[F(1,8)<1]$. Comparisons of the $\mathrm{CS}+$ versus the NS latencies at the 24-h interval were significant $[t \mathrm{~s}(9)>9.33, p<.0001]$.

\section{Discrete-Trial Chemosensory Conditioning Selectively Increased Bite-Strike Latencies to CS1, Regardless of Type of US Used}

In contrast to the results of Experiments 1-4, in which continuous prolonged exposures to extracts were used, discrete-trial chemosensory conditioning produced reasonably selective increases in bite-strike latencies to the $\mathrm{CS}+$ paired with a rotational/shaking US. As has been reported previously (Farley et al., 1990; Farley et al., 1997), these effects were not entirely specific to the $\mathrm{CS}+$. Bite-strike latency increases also occurred to a chemosensory NS. However, these increases to the NS were significantly smaller than those that occurred to the $\mathrm{CS}+$.

Since the results of the present experiment accorded well with those obtained for animals sampled before 1990 (Farley et al., 1990), the general characteristics of discrete-trial chemosensory aversion learning for Hermissenda appear to be stable. Thus, any naturally occurring variations among the different populations sampled by Rogers et al. (1996) prior to late 1996 and those we sampled here (November 1996-June 2002) are likely to be inconsequential for the main trends in contextual conditioning observed in Experiments 1-3.
Two other differences in the results for the $\mathrm{CS}+$ in the contextual versus discrete-trial experiments warrant comment. First, the latency increases cumulated with training days in the discrete-trial, but not in the contextual, conditioning experiments. This was more apparent for the first- versus three-trial test results. For the latter, the repeated testing of foods within a session produced transient, response-decrementing effects that tended to obscure training-associated changes that occurred across conditioning sessions. For example, with discrete-trial conditioning (Figures 5 and 6), the maximal latency increases to the CS + were observed following either Test/Training Day 2 or 3 . In contrast, with contextual CS conditioning (Figures 2 and 3), CS + latencies were usually asymptotic following the first training/test day. An exception to this generalization occurred when scallop was used as the contextual CS + in Experiment 3 (Figure 3B). Here, latency increases continued to increase up through the final (third) training day.

A second difference concerns the magnitude of the latency increase at the 24-h retention interval (Test Day 4) versus that observed at the 2 -h retention interval following the conclusion of training (Day 3). For the contextualconditioning results (Figures 1-3), the latencies generally showed a substantial decline between 2 and $24 \mathrm{~h}$. When the combined results are considered for the first- and the threetrial data (panels A and D of Figures 1-3), an average decline of $\sim 39 \%$ was observed for both the CS + and the NS. For the discrete trial results (panels A and D of Figures 5 and 6), the average declines were smaller: $20 \%$ for the CS+ and $14 \%$ for the NS. One interpretation of this pattern is that discrete-trial-conditioned animals "forgot" less of their previous conditioning experience with the CS+ across the $\sim 22 \mathrm{~h}$ that separated the final two test sessions.

Alternatively, the greater latency decrease for contextversus discrete-trial-conditioned groups might reflect response measurement considerations. Because the latencies to the $\mathrm{CS}+$ for context-conditioned animals were generally greater than those for discrete-trial-conditioned animals at the end of the third training/test day (i.e., final 2-h retention test), it might be argued that there was room for a greater decline in performance over the ensuing $22 \mathrm{~h}$ for these animals. We cannot exclude this explanation, and the possibility remains that the greater latency decrement for the context-conditioned animals was only an apparent one and did not reflect a true learning/retention difference. This greater room for decline explanation is not without problems, however. As presently formulated, it does not easily explain why the CS+ response latencies for the two groups would end up at approximately the same level, well above the original baseline values (i.e., the latencies did not decline to the floor).

Thus, we propose that the relative lack of cumulative increases in response latencies and, apparently, more rapid forgetting for context-conditioned animals reflect a common process. Both can be explained by supposing that the prolonged CS exposures of contextual conditioning produced transient, nonassociative, and nonselective 


\section{A}

EXPERIMENT 5B: FIRST TRIAL (COMBINED RESULTS)

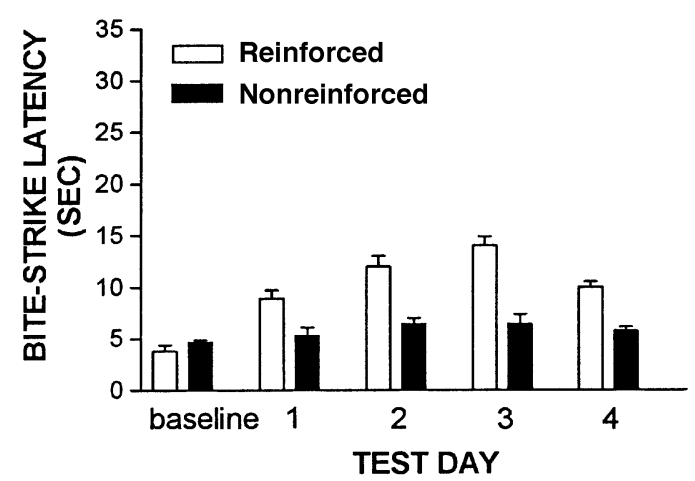

B
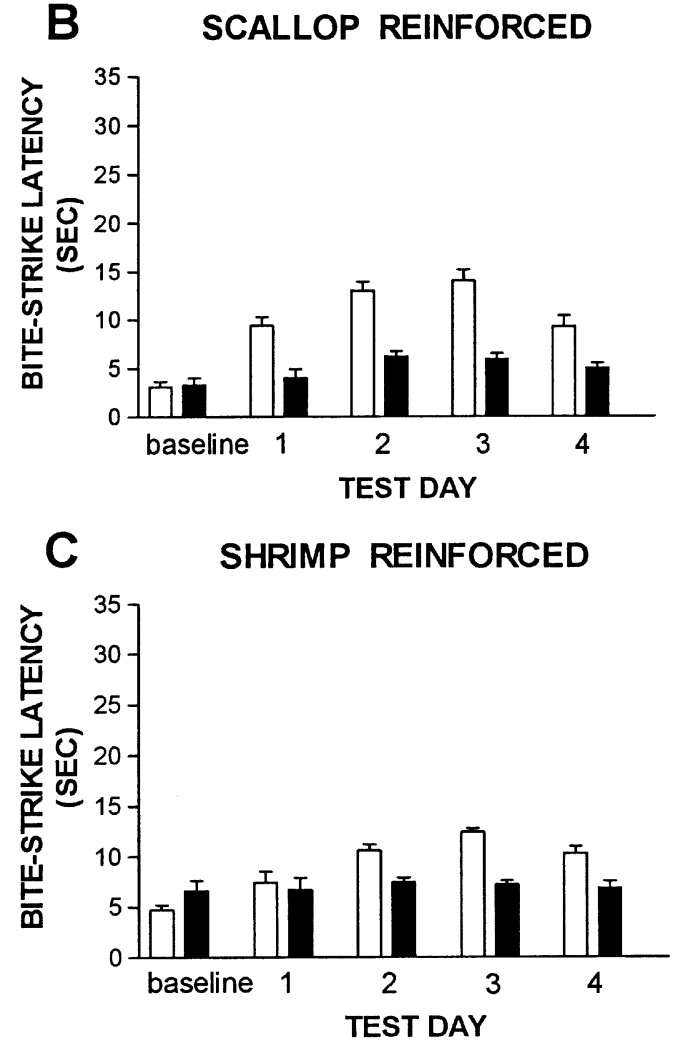

D EXPERIMENT 5B: THREE TRIALS (COMBINED RESULTS)
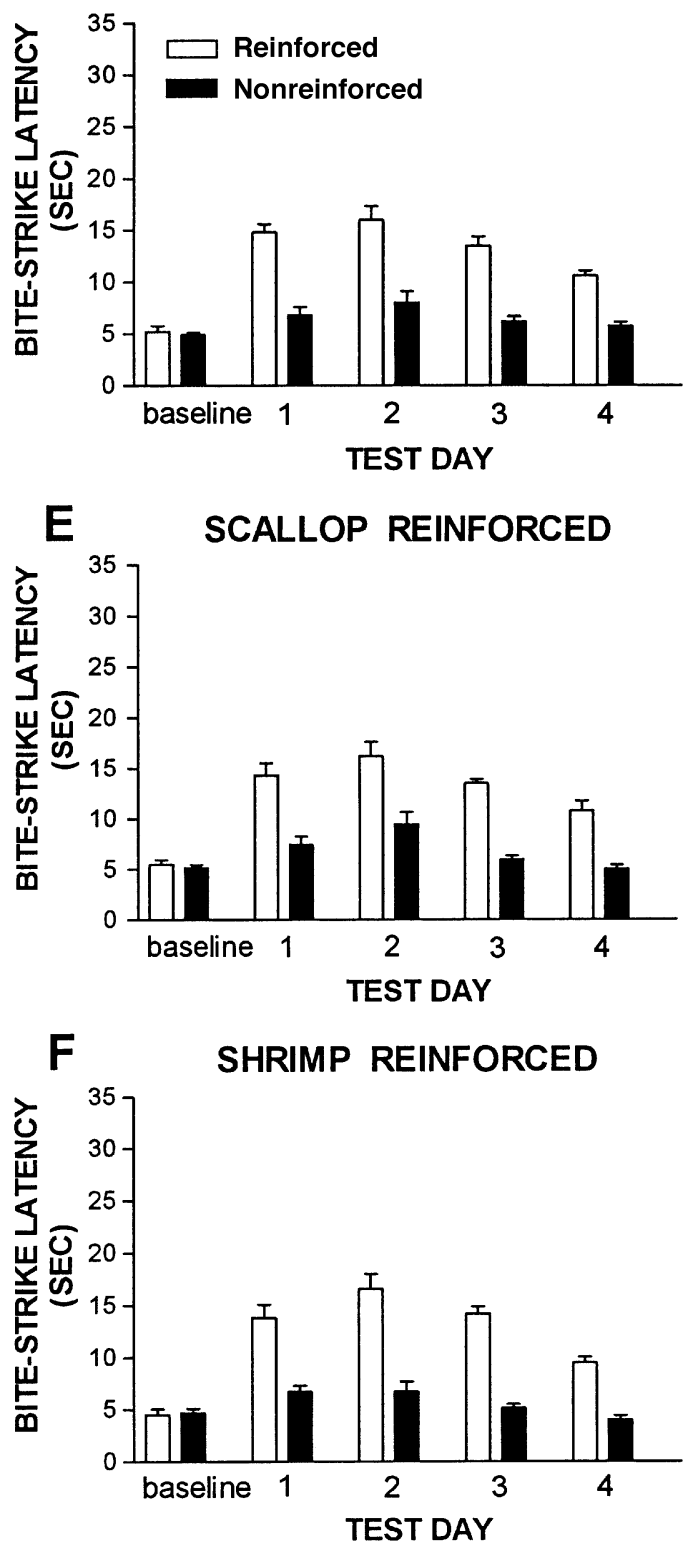

Figure 6. Test results of discrete-trial chemosensory conditioning in Experiment 5B. The animals were given three successive daily training sessions. During each session, the animals received 30 discrete-trial presentations of a chemosensory extract (CS + ) paired with orbital rotation/shaking (US). The final concentrations of the shellfish extracts were $2.2 \mathrm{~g} / \mathrm{mL}$. The animals were also tested with a second shellfish extract that they had not been exposed to during training sessions. First-trial results appear on the left $(A-C)$, and three-trial results appear on the right (D-F). Panels $A$ and $D$ present the mean latency data (in seconds) for reinforced and nonreinforced chemosensory cues across training days and at a 24-h retention interval. The data have been combined without regard as to which cue served as the reinforced or nonreinforced context. Panels $B, C$ and $E, F$ display mean acquisition and retention data, with the data separated as to the type of chemosensory cue that was reinforced (i.e., scallop [B,E] or shrimp [C,F]). Error bars indicate standard errors.

increases in bite-strike latencies to both reinforced and nonreinforced contextual CSs. Such increases might arise from the greater sensory adaptation, habituation, and satiation that prolonged context exposures would be expected to produce. We would expect such effects to be greatest shortly following training (e.g., at a 2-h retention interval), thereby leading to the asymptotic and nonselective response latency increases at the end of Day 1 for context-conditioned animals. We would also expect these effects to dissipate considerably over the ensuing $22 \mathrm{~h}$, 

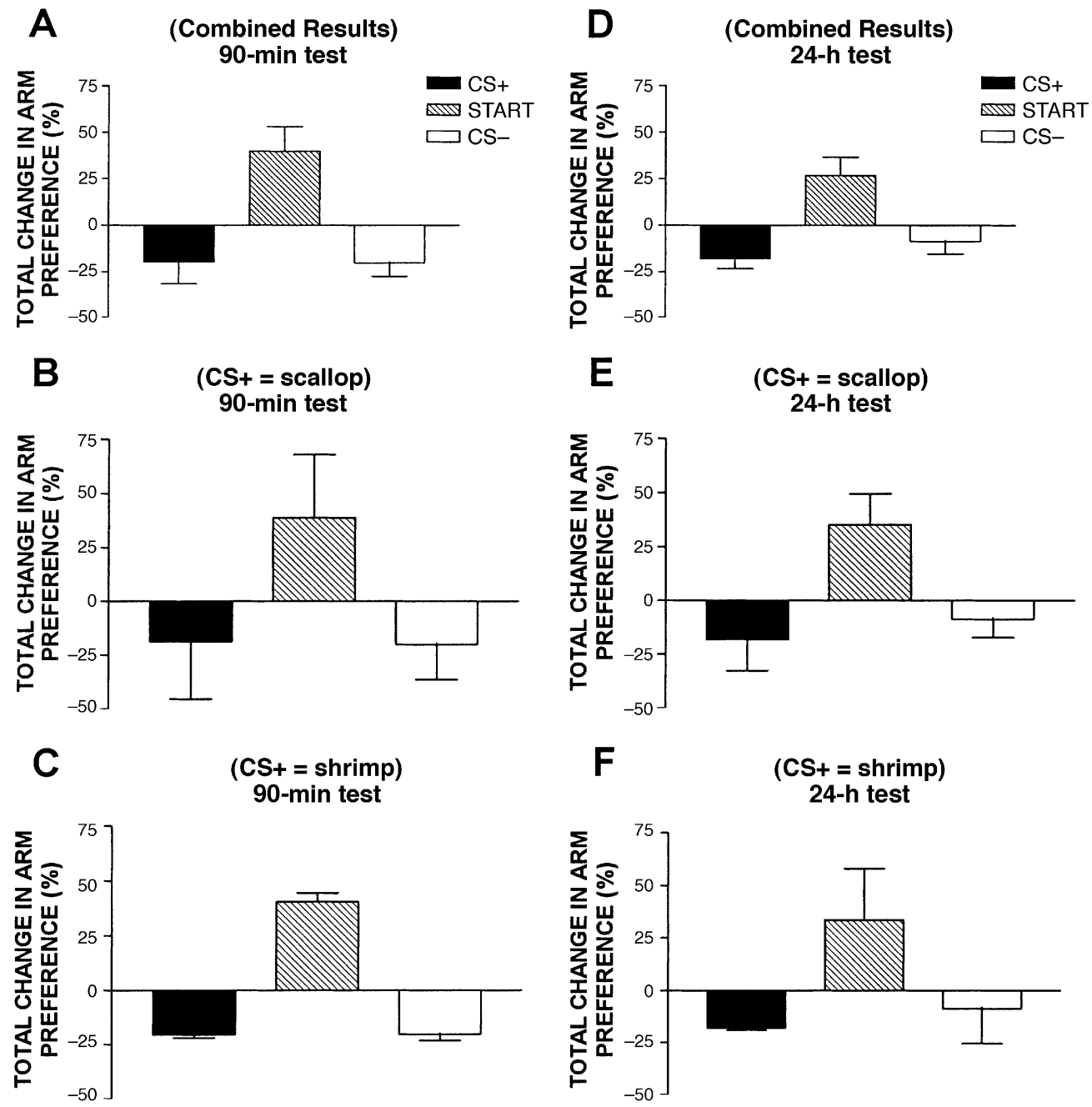

Figure 7. Y-maze preference test results obtained $90 \mathrm{~min}(\mathrm{~A}-\mathrm{C})$ or $24 \mathrm{~h}$ (D-F) following the conclusion of attempted differential chemosensory contextual conditioning in Experiment 6 . These results are based on the behavior of those 6 animals (of an initial 30) that sampled both arms of the Y-maze. The animals were trained as in Experiment 3. Context-US associations were evaluated using changes in arm (stimulus) preference as a measure. Following a 15-min duration test trial, the percentage of time spent in each arm was calculated, and the differences between pre- and postconditioning scores were determined for the entire 15min test period. Panels $A$ and $D$ present the mean changes in preference (i.e., difference in percentages of time between pre- and posttraining scores) for the arms containing the chemosensory stimulus that had been reinforced $(\mathrm{CS}+)$, the stimulus that was nonreinforced $(\mathrm{CS}-)$, or the start arm of the maze. The data have been combined without regard as to which cue animals were conditioned to. Panels $B, E$ and $C, F$ present the results separated as to which cue was used as the CS+ (i.e., scallop or shrimp). Four animals contributed to each data set in panels $B, E$ and $C, F$. Error bars indicate standard errors.

thus leading to the large decline in latencies between Test Days 3 and 4 . To the extent that such nonassociative processes altered the pattern of neural processing required for successful associative chemosensory aversion conditioning, we might further anticipate less of an associative contribution to the response latency increases to CS + exhibited by context-conditioned animals. Processes such as sensory adaptation, habituation, and satiation presumably also occur during discrete-trial training and may explain the nontrivial increases to an untrained/nonexposed cue (NS). The fact that such changes are reliably smaller to the NS than to the CS+ with the discrete-trial procedure but no such specificity could be detected here for the contextual-conditioning procedure is one reason for thinking that such nonassociative processes play less of a role in the discrete-trial procedure.

\section{EXPERIMENT 6}

Although we were unable in earlier experiments to detect selective decreases in bite-strike latency to the CS+ for context-conditioned animals, even if we had been 
successful such a result would not in itself have provided unambiguous evidence for the occurrence of associative learning. As we have argued elsewhere (Farley \& Alkon, 1985, 1987; Farley et al., 1997) — and as Rogers et al. (1996) themselves acknowledged - differential responding to CS + versus CS- (or NS) need not necessarily imply that an association has been formed between the $\mathrm{CS}+$ and the US. Sensitization coupled with differential habituation can, in principle, lead to a similar outcome.

As applied to the results in Rogers et al. (1996), it might be argued that repeated aversive shaking/rotation sensitized feeding reflexes (thereby decreasing bite-strike latencies to the CS+ and the CS-), while prolonged CS exposure resulted in response-decrementing processes (e.g., habituation, sensory adaptation, or satiation) that acted to increase latencies to both stimuli. If one further assumes that the (combined) decrementing processes were stronger than sensitization and, further, that the presentation of the US disrupted habituation to the contextual CS that it accompanied (i.e., a protection from habituation effect; Pfautz, Donegan, \& Wagner, 1978), the very small, selective response latency decreases to the $\mathrm{CS}+$ might be explained. Because of this interpretative ambiguity concerning the effects of pairings of a CS and a US, it is important to consider the results of other response measures that bear on whether the particular pattern of changes to a $\mathrm{CS}+$ and a $\mathrm{CS}-/ \mathrm{NS}$ arises from associative or nonassociative learning processes.

Rogers et al. (1996) reported results for two additional response measures that they felt buttressed the case for the occurrence of associative learning during contextual conditioning. Contextually conditioned animals showed a facilitation of a preparatory clinging response (elicited by the US of shaking). The latency to fall off a substrate was longer when animals were tested in the presence of the reinforced versus nonreinforced contextual cue (Figure 2 in Rogers et al., 1996). But because latencies to cling to the substrate in the absence of a chemosensory stimulus (or in the presence of a neutral CS) were not reported, it is unclear whether the latency differences in the presence of the CS + versus the CS - reflected a genuine facilitation of clinging by the $\mathrm{CS}+$, a disruption of clinging by the $\mathrm{CS}-$, or both. Moreover, even if the latencies exhibited to the shaking US in the presence of the $\mathrm{CS}+$ should prove longer than those observed to shaking in ASW or shaking in the neutral CS, the results might be explained by the same class of account, emphasizing sensitization and protection from habituation, that has been advanced to explain the bite-strike latency results (Farley et al., 1997). Therefore, a reinforced context food stimulus would have been protected from habituation and, thus, more likely to elicit feeding and associated postural changes compatible with substrate adherence (see Ram, Noirot, Waddell, \& Anderson, 1988, for a demonstration that food stimuli inhibit locomotion of hungry Hermissenda). Therefore, the enhanced preparatory clinging result is no more definitive in discriminating between associative and nonassociative accounts of changes to a contextual CS + than was the pattern of results for the bite-strike latency measure.

However, a third result reported by Rogers et al. (1996, Experiment 2) cannot be explained by the preceding nonassociative account and thus, in principle, provides strong evidence for associative learning. Rogers et al. measured the preferences of animals for reinforced versus nonreinforced food stimuli and reported that following contextual conditioning, animals selectively avoided the food whose extract had been used as the CS+. Preference testing in this experiment was accomplished by placing an animal in the start (center) arm of an underwater Y-maze, with the two choice arms baited with the foods used as the

\section{A BOTHREPLICATIONS: 90-MIN TEST}
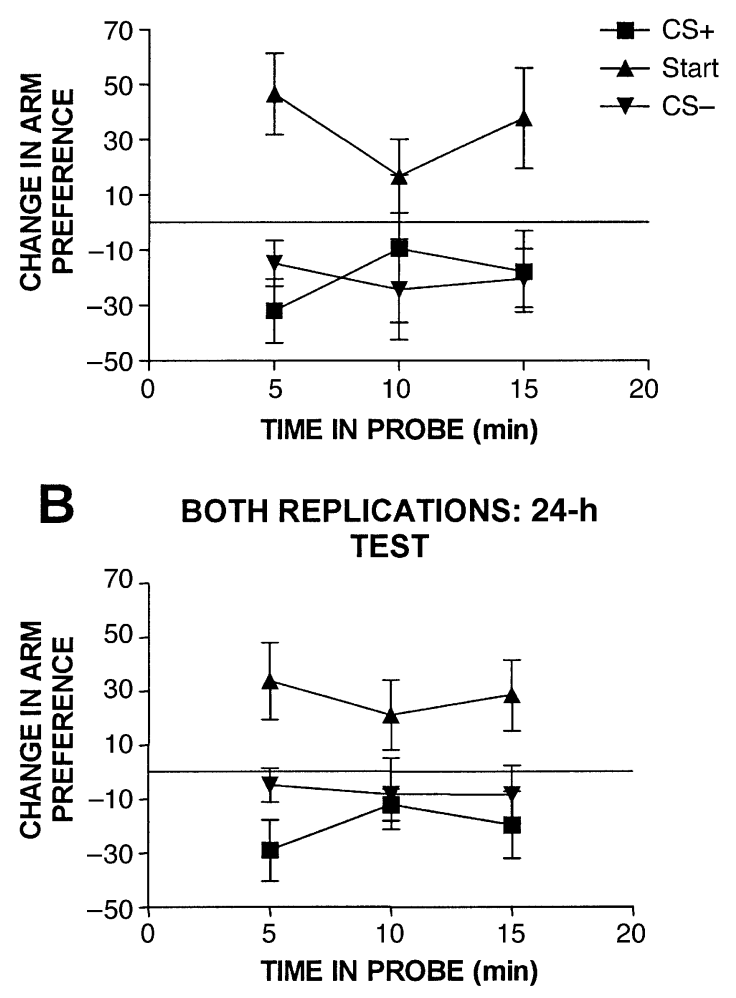

Figure 8. Y-maze preference test results obtained $90 \mathrm{~min}$ (A) and $24 \mathrm{~h}$ (B) following the conclusion of attempted differential chemosensory contextual conditioning in Experiment 6. These results are based on the behavior of those 8 animals (of an initial 30) that sampled both arms of the Y-maze. Context-US associations were evaluated using changes in arm (stimulus) preference as a measure. Following a 15-min test trial, the percentage of time spent in each arm was calculated, and the differences between pre- and postconditioning scores were determined across the test in 5-min blocks. Each panel presents the mean changes in preference (i.e., difference in percentages of time between pre- and posttraining scores) for the arms containing the chemosensory stimulus that had been reinforced $(\mathrm{CS}+)$, the stimulus that was nonreinforced $(\mathrm{CS}-$ ), or the start arm of the maze. The data have been combined without regard as to which cue the animals were conditioned to. Error bars indicate standard errors. 
CS + and the CS -, respectively. Rogers et al. (1996, Figure 3 ) reported that following conditioning, and measured relative to baseline, contextually conditioned animals showed a moderate decrease in the percentage of time spent in the arm baited with the reinforced food and small increases in the percentage of time spent in the start arm and the arm baited with the nonreinforced food.

We therefore attempted to repeat this result for contextconditioned animals, in the hope not only of demonstrating selective changes to the $\mathrm{CS}+$, but also of obtaining evidence that such a change reflected a contribution of associative-learning processes.

\section{Method}

\section{Subjects}

Thirty adult animals were used. As described in Rogers et al. (1996), the animals were fed daily with small ( 1.5-mg) pieces of Hikari Gold fish food, $1 \mathrm{~h}$ before their dark cycle. Twenty-four hours prior to the first test/training session, the animals were food deprived and received no further feedings.

\section{Apparatus}

The animals were conditioned in the same apparatus as that in Experiments 1-4. Preference testing occurred in Y-mazes. Two separate mazes were constructed of clear Plexiglas. The tracks in each arm measured $65 \mathrm{~mm}$ long, $15 \mathrm{~mm}$ wide, and $25 \mathrm{~mm}$ deep, with each arm separated from the other by a $120^{\circ}$ angle. The ends of the two choice arms contained a sample of either shrimp or scallop meat, with access to the food restricted by a nylon mesh barrier. A single animal was placed into each maze, submerged in $16^{\circ} \mathrm{C}$ ASW. Each maze was covered with a clear Plexiglas top. The apparatus was placed $35 \mathrm{~cm}$ below a low-light CCD video camera (Panasonic WV-B1204) that was used to monitor the animal throughout a test trial and was housed in a refrigerator maintained at $15^{\circ} \mathrm{C}$. All the animals were tested in the presence of the red safety light.

The following differences in subject housing and apparatus distinguish this experiment from that in Rogers et al. (1996). Rogers et al. used a 10:14-h light:dark cycle for their home aquaria $\left(12^{\circ} \mathrm{C}\right)$, whereas we used a $12: 12$-h cycle for our aquaria $\left(14^{\circ} \mathrm{C}\right)$.

\section{Procedure}

Food sample. Standard $(2.2 \mathrm{~g} / \mathrm{mL})$ extract solutions used during contextual conditioning were prepared as in Experiments 2 and 3.

Each animal's choice behavior in a Y-maze was first tested $24 \mathrm{~h}$ before the first prospective training day. Two posttraining tests were also administered; the first was given 90 min following the conclusion of training, and the second at a $24-h$ retention interval. Food detection and preference were assessed by measuring the percentage of the total 15-min test period spent in each arm (i.e., start, left, and right arms) of the maze. A continuous choice procedure was used in which the animal was free to enter, leave, or reenter any arm of the maze at any time. Arm designation (i.e., scallop or shrimp) was counterbalanced across animals but remained the same for individual animals. Arm entry and the percentage of time spent in each arm were determined from videotape by a rater without knowledge of the specific conditioning history of the animal.

In scoring the videotapes, the criteria used in Rogers et al. (1996) were applied: An animal was judged as having entered (or exited) an arm when the front one third of its body passed the arm opening (as indicated by marks on the maze). We also tabulated the number of bouts of attempted food contact. A bout was defined as the animal's moving to the end of a baited arm and making physical contact (for $2 \mathrm{sec}$ or more) with the mesh barrier covering the food sample. Clear movement away from the food sample, for a distance $>5 \mathrm{~mm}$ and an intervening period of $10 \mathrm{sec}$ or more without barrier contact, was required before an additional bout of approach and contact was scored

Behavioral testing and conditioning. Following their initial food preference test, the animals that had sampled both baited arms of the Y-maze were exposed to chemosensory contextual conditioning. These animals were conditioned with 150 US presentations (50 per day for 3 days), using the procedures described for Experiments 2 and 3. Experiment 6 was conducted in three separate replications ( $n=10$ per replication) during February 2000, April 2000, and June 2002. Those animals receiving contextual conditioning in Replication 1 were trained with scallop as the CS + and shrimp as the CS - . Cue assignment was reversed in Replication 2. In Replication 3 , half the animals $(n=5)$ were trained with scallop as the $\mathrm{CS}+$ and shrimp as the $\mathrm{CS}-$, with the cue assignment reversed for the other 5 animals. No bite-strike tests were administered in these experiments.

\section{Statistical Analysis}

For each Y-maze test, we used the continuous time measure described in Rogers et al. (1996). With this measure, three scores (one for each arm) were computed for each animal by subtracting the percentage of time spent in each arm during the postconditioning test trial from that during the preconditioning test trial. Changes in arm preference across 5-min blocks were determined using a twofactor ANOVA with a single repeated measure. Factor 1 of the ANOVA was the maze arm (i.e., reinforced, nonreinforced, or start arm), and Factor 2 was the time block during the test trial (i.e., 5, 10 , or $15 \mathrm{~min}$ ). In addition, the total change in arm preferences across the entire 15-min test trial was analyzed using a one-factor ANOVA (i.e., reinforced, nonreinforced, or start arm).

\section{Results}

Of the 30 animals screened in the Y-maze, 8 failed to move from the start area. Another 14 (6, 4, and 4 from Replications $1-3$, respectively) entered only one arm. Only 8 animals $(3,3$, and 2 from Replications $1-3$, respectively) sampled both baited arms and provided interpretable choice data. Our finding that $73 \%$ of the animals tested failed to provide unambiguous preference data contrasts with the results in Rogers et al. (1996), who reported that 20 of 23 animals tested sampled both arms.

For the 8 animals that sampled both arms, an overall preference for scallop was evident, with 7 of 8 animals exhibiting a choice proportion $>.44$ (chance level of .33). Similarly, for the 14 animals that sampled only one baited arm, 10 exhibited a choice proportion $>.69$ for scallop, 2 animals never entered the scallop arm, and 2 animals showed chance-level choice proportions for scallop (.34 and .31).

For the 8 animals that sampled both arms during their initial test and continued in the experiment, context-US associations were evaluated using the measure of changes in arm preference (Rogers et al., 1996). Ninety minutes following conditioning, a significant increase in preference was exhibited for the start $\operatorname{arm}[t(7)=3.05, p<.05$; Figure 7A]. Preference reductions were apparent for both of the other arms (Figure 7A). But all of these differences failed to reach significance $[t(7)=1.60$ and 1.75 for $\mathrm{CS}+$ and CS - , respectively; $p>$.13], largely because of the small $n$. The same general pattern was exhibited to each baited arm, regardless of whether the animals were trained 
with scallop or shrimp as the CS+ (Figures 7B and 7C). The change in arm preference for the reinforced, nonreinforced, and start arms differed $[F(2,17)=10.41, p<$ $.002]$, with the change score for the start arm differing from those for the baited arms. The scores for the two baited arms did not differ.

From observation of the videotapes, it became clear that the increase in preference for the start arm was only an apparent one, since the animals were generally inactive 90 min following conditioning. The temporal characteristics of choice during the postconditioning test (Figure 8A) supported this interpretation. During the first 5-min period, when the greatest increase in preference to the start arm was recorded, 4 of 8 animals failed to move. Three of these animals were also inactive during the next 5-min period. For all 8 animals, the latency $(M \pm S E M)$ to first leave the start arm was $0.72 \pm 0.37 \mathrm{~min}$ during the pretest and $6.81 \pm 2.54$ min during the 90 -min postconditioning test $[t(7)=3.62, p<.025]$. Thus, the apparent reductions in preference observed to the $\mathrm{CS}+$ and the $\mathrm{CS}-$ during the first $10 \mathrm{~min}$ of testing did not appear to be genuine and were probably artifacts of inactivity and the reduction in sampling behavior. By the beginning of the final 5-min period, 5 of 8 animals had moved away from the start arm and had sampled one or both of the baited arms. These animals either returned to the start area and remained there or locomoted back and forth between the two baited arms. An ANOVA revealed consistent differences in the preference changes observed to the arms [main effect of arm: $F(2,54)=14.87, p<.0001]$, with the general pattern of changes remaining consistent across the three 5 -min sampling periods [no main effect of time, $F(2,54)<1$; no interaction with arm, $F(2,54)<1]$.

This pattern contrasts with that in Rogers et al. (1996). During the first 5 min of testing in Rogers et al.'s study, the animals spent less time in the start and reinforced arms than during baseline. They thus appeared to be actively avoiding these two arms (or alternatively, approaching the nonreinforced arm). During the last $10 \mathrm{~min}$ of the test, the animals no longer chose the nonreinforced arm but, instead, chose the center (start) arm, while continuing to avoid the reinforced arm.

The number of distinct arm entries made prior to conditioning by the 8 animals that completed training varied greatly, ranging from 2 to 12 , for an average of $6.3 \pm 4.1$. In contrast, $90 \mathrm{~min}$ following conditioning, the average number of arm entries was only $1.5 \pm 0.9$ (range, $0-3$ ). Some recovery of maze exploration occurred on the following day (24-h test), but even here the number of entries $(2.8 \pm 1.6)$ was significantly less than during pretraining $[t(7)=3.97, p<.01]$. A major effect of chemosensory contextual conditioning appeared to be a general sluggishness, expressed as greatly reduced sampling of the baited arms of the maze.

A qualitatively similar pattern was observed at the 24$\mathrm{h}$ retention interval (Figure 7D). Although preference for the start arm was nominally greater at $24 \mathrm{~h}$, relative to the pretraining test level, the difference just missed exceeding conventional significance levels $[t(7)=2.33$, $p>.06]$. Similarly, reductions in preference to the CS+ arm and the CS - arm were observed. But neither difference was significant [for CS+, $t(7)=2.25, p>.06$; for CS $-, t(7)=1.42, p>.20]$. The same pattern was evident regardless of which cue was reinforced (Figures $7 \mathrm{E}$ and $7 \mathrm{~F}$ ). In general, the choice pattern changed little across the 15-min test (Figure 8B). Although the animals were more active at $24 \mathrm{~h}$ than at 90 min after training, their latencies to leave the start area were significantly longer than those during the pretest $[3.8 \pm 1.8 \mathrm{~min}$; $t(7)=2.90, p<.05]$.

In summary, both the 90-min and 24-h test results failed to provide evidence for a selective decrease in preference for the CS+. Moderate decreases in preference for both the CS+ and the CS- were observed. The increased latencies and the failure to sample both arms of the maze suggest that the preference changes were by-products of a general decrease in activity. Our results failed to support the view that Y-maze preference changes reflect the expression of an associative-learning process engaged by chemosensory contextual conditioning. Our results are more parsimoniously explained by an account that emphasizes nonspecific decrements in feeding motivation and locomotor activity produced by prolonged exposures to concentrated food extracts.

\section{Discussion}

Although disappointed by our failure to observe reduced preference to a context-conditioned CS + in the Ymaze preference test, we were not entirely surprised. Early in our development of the discrete-trial chemosensory conditioning procedure, we had explored the utility of food preference tests for hungry Hermissenda, using both T- (Farley et al., 1990) and Y-mazes (Farley \& Grover, 1989) similar to those used here and by Rogers et al. (1996). As was the case here, we previously had found that choice behavior for foods were unreliable. A conspicuous problem in past and present studies was that during baseline tests (prior to any conditioning), many animals either failed to move from the center start area (no choice) or failed to sample both arms of the maze. Additional behaviors often observed that undermine our confidence in this measure included the animals' entering just the initial portion of a baited arm, failing to approach and contact the food, and becoming quiescent for the duration of the observation period. We note that Rogers et al. did not report whether their animals contacted or attempted to ingest the food pieces used to bait the arms of their Y-mazes.

We are not the only ones to have encountered these difficulties. Avila (1998) reported extensively on the chemotactic ability of laboratory-reared Hermissenda to detect foods in Y-mazes. Using a single-choice Y-maze (one arm 
baited, one unbaited), Avila first tested whether the food that hungry animals had eaten for 2 weeks prior (their conditioning diet) had any influence on their choice behavior. Specifically, would the animals choose a baited arm? The animals fed one of six diets were offered one of those food items versus a blank arm, for 24 distinct diet/test combinations. In only 5 of the 24 conditions did the animals detect the presence of food (i.e., show a significant preference for the baited arm). For three of the six conditioning diets, the animals detected the food they had been fed, but no other. For one diet, the animals were able to detect both that food and one other. For the two remaining diets, the animals were unable to detect any foods. A striking feature of Avila's results was the large percentage of trials on which no choice was made: $29 \%$ (112 of 385) of all the trials, $25 \%$ (21 of 85 ) of trials for the 5 diet/test food combinations where food was detected, and 30\% (91 of 300) of trials for the 19 diet/test food combinations for which food was not detected.

Avila (1998) also determined whether animals would prefer their diet food to a novel food, using a double-choice Y-maze (both arms baited, but with different foods). In only 2 of 10 conditions examined did the animals show a preference for the food they had been fed (the animals fed Tubularia preferred it to Metridium, but none of the other four foods tested; the animals fed Mytilus preferred it against Tubularia). The animals failed to make choices in the Y-maze on a moderate percentage of trials: $18 \%$ of the total trials (22 of 124) of the total trials, 13\% (3 of 23) of trials for the diet/test combinations where a preference was shown, and 19\% (19 of 101) trials for the diet/test combinations where no preference was exhibited. Although the number of no choices in Avila's study is large enough to warrant concern, they were nonetheless considerably smaller than those in our study. Two procedural differences seem likely to account for this: (1) the use of relatively low temperatures $\left(11^{\circ} \mathrm{C}\right.$ in Avila vs. $16^{\circ} \mathrm{C}$ here and in Rogers et al., 1996) and (2) Avila's use of flow-produced chemosensory gradients.

We do not dispute Avila's (1998) general conclusion that diet history can, under limited conditions (namely, a diet of hydroids, a preferred natural food), lead to successful chemotactic choice in Hermissenda. However, we continue to be struck by Hermissenda's poor ability to discriminate and recognize different foods in tests (e.g., Y-maze preference behavior) that depend on distance chemoreception, as was originally emphasized by Agersborg (1922).

In our hands, the Y-maze choice test is an unreliable and insensitive means of testing food preferences for the majority of adult Hermissenda. Our failure to replicate Rogers et al.'s (1996) Y-maze results, the large percentage of no-choice trials during baseline, and the limited evidence for successful distance chemoreception in Avila's (1998) study encourage considerable skepticism as to whether current choice test methods for Hermissenda are sufficiently reliable to detect associative learning to chemosensory stimuli in these animals.

\section{GENERAL DISCUSSION}

\section{Contextual Chemosensory Conditioning Produces Nonselective Increases in Bite/Strike Latencies}

Our major findings can be summarized simply. We observed large ( $>5-\mathrm{sec})$ increases in bite/strike latencies to both reinforced and nonreinforced chemosensory cues, following contextual conditioning of Hermissenda. We thus failed to obtain clear evidence for associative learning with this procedure. Although it is conceivable that more replications and larger $n$ s might eventually yield significant differences in animals' responses to CS + versus CS-, there is little reason to believe that such differences would duplicate the pattern reported in Rogers et al. (1996): small bite-strike latency decreases to a CS + of scallop and moderate bite-strike latency increases to a CS - of shrimp.

We also failed to observe decreased preference to the $\mathrm{CS}+$ in $\mathrm{Y}$-maze tests. The problems here were twofold. First, during baseline, many animals either failed to move from the start area, or entered only one arm of the maze and, thus, cannot with certainty be said to have sampled both alternatives. Second, for those active animals that did sample both arms in the baseline test, no clear decrease in preference to the $\mathrm{CS}+$ was observed during either of two postconditioning tests. The small decreases that did occur were not significantly different from those to the CS-. Overall, it appeared that the animals' preference for the start arm increased, probably because of decreased activity and sampling behavior.

For the most part, we conducted contextual conditioning, as well as tests of bite/strike and choice behavior in the Y-maze, as described by Rogers et al. (1996). Our attempts to reproduce their results encompassed a variety of experimental conditions. Although subtle procedural differences between the two laboratories might, in principle, account for these discrepancies, we have no insights at present as to which ones might be important. Additional research will be required to establish the conditions under which the above-mentioned behavioral differences arise and to ascertain whether genuine chemosensory contextual conditioning of Hermissenda can be routinely produced.

\section{REFERENCES}

Agersborg, H. P. K. (1922). Some observations on qualitative chemical and physical stimulation in nudibranchiate mollusks with special reference to the role of the "rhinophore." Journal of Experimental Zoology, 36, 423-444.

Alexander, J. E., Audesirk, T. E., \& Audesirk, G. J. (1982). Rapid, nonaversive conditioning in a freshwater gastropod: Effects of temporal relationships on learning. Behavioral \& Neural Biology, 36, 391-402.

ALKON, D. L. (1974). Associative training of Hermissenda. Journal of General Physiology, 64, 70-84.

AvILA, C. (1998). Chemotaxis in the nudibranch Hermissenda crassicornis: Does ingestive conditioning influence its behavior in a Ymaze? Journal of Molluscan Studies, 64, 215-222.

Balaban, P., \& Bravarenko, N. (1993). Long-term sensitization and 
environmental conditioning in terrestrial snails. Experimental Brain Research, 96, 487-493.

Balsam, P. D., \& Tomie, A. (1985). Context and learning. Hillsdale, NJ: Erlbaum.

BARKer, L. M., Best, M. R., \& DomJAN, M. (1977). Learning mechanisms in food selection. Waco, TX: Baylor University Press.

Colwill, R. M., AbSher, R. A., \& RoberTs, M. L. (1988). Context-US learning in Aplysia californica. Journal of Neuroscience, 8, 44344439.

Cowan, T. M., \& Siegel, R. W. (1986). Drosophila mutations that alter ionic conduction disrupt acquisition and retention of conditioned odor avoidance response. Journal of Neurogenetics, 3, 187-201.

Croll, R. P., \& ChaSE, R. (1977). A long-term memory for food odors in the land snail Achatina fulica. Behavioral Biology, 19, 261-268.

Croll, R. P., \& CHASE, R. (1980). Plasticity of olfactory orientation to foods in the snail Achatina fulica. Journal of Comparative Physiology, 136, 267-277.

Crow, T., \& AlKon, D. L. (1978). Retention of an associative behavioral change in Hermissenda. Science, 209, 412-414.

FARLEY, J., \& AlKoN, D. L. (1980). Neural organization predicts stimulus specificity for a retained associative behavioral change. Science, 210, 1373-1375.

FARLEY, J., \& ALKON, D. L. (1982). Associative neural and behavioral change in Hermissenda: Consequences of nervous system orientation for light- and pairing-specificity. Journal of Neurophysiology, 48, 786-807.

Farley, J., \& AlKon, D. L. (1985). Cellular mechanisms of learning, memory, and information storage. Annual Review of Psychology, $\mathbf{3 6}$, 419-494.

FARLEY, J., \& AlKon, D. L. (1987). Cellular analysis of gastropod learning. In A. J. Greenberg (Ed.), Cell receptors and cell communication (pp. 220-266). Basel: Karger.

Farley, J., \& Grover, L. M. (1989). [Choice behavior assessments of chemosensory aversion learning in Hermissenda]. Unpublished raw data.

Farley, J., Grover, L. M., Sun, L., Huang, S. S., Eisthen, H. L., Girolami, C., \& Wu, R. (1990). Chemosensory conditioning of Hermissenda crassicornis. Behavioral Neuroscience, 104, 583-596.

FARLEY, J., \& JIN, I. (1997). Potentiation of phototactic suppression in Hermissenda by compound conditioning results in potentiated excitability changes in type B and A photoreceptors. Behavioral Neuroscience, 111, 309-319.

FARLEY, J., R EASONER, H., \& JANSSEN, M. (1997). Potentiation of pho- totactic suppression in Hermissenda by a chemosensory stimulus during compound conditioning. Behavioral Neuroscience, 111,320341.

Garcia, J., Kimmeldorf, D. J., \& Koelling, R. A. (1955). Conditioned aversion to saccharin resulting from exposure to gamma radiation. Science, 122, 157-158.

GELPERIN, A. (1975). Rapid food-aversion learning by a terrestrial mollusk. Science, 189, 567-570.

KemenES, G., \& Bendamin, P. R. (1989). Appetitive learning in snails shows characteristics of conditioning in vertebrates. Brain Research, 489, 163-166.

MPITSOS, G. J., Collins, S. D., \& McClellan, A. D. (1978). Learning: A model system for physiological studies. Science, 199, 497-506.

MpITsos, G. J., \& Davis, W. J. (1973). Learning: Classical and avoidance conditioning in the mollusc Pleurobranchaea. Science, $\mathbf{1 8 0}$ 317-320.

Peschel, M., Straub, V., \& Teyke, T. (1996). Consequences of foodattraction conditioning in Helix: A behavioral and electrophysiological study. Journal of Comparative Physiology, 178, 317-327.

Pfautz, P. L., Donegan, N. H., \& Wagner, A. R. (1978). Sensory preconditioning versus protection from habituation. Journal of Experimental Psychology: Animal Behavior Processes, 4, 286-295.

RaM, J. L., NoIrot, G., WadDEll, S., \& ANDERSon, M. (1988). Singleness of action in the interactions of feeding with other behaviors in Hermissenda crassicornis. Behavioral \& Neural Biology, 49, 97111.

Riley, A., \& TuCK, D. L. (1985). Conditioned taste aversions: A behavioral index of toxicity. In N. Braverman \& P. Bronstein (Eds.), Experimental assessments and clinical applications of conditioned food aversions (Vol. 443, pp. 272-292). New York: New York Academy of Sciences.

Rogers, R. F., Schiller, K. M., \& Matzel, L. D. (1996). Chemosensorybased contextual conditioning in Hermissenda crassicornis. Animal Learning \& Behavior, 24, 28-37.

SUZUKI, N. (1968). Odor discrimination in the land snail. Zoological Magazine, 77, 178-184.

Whelan, H. A., \& McCrohan, C. R. (1996). Food-related conditioning and neuronal correlates in the freshwater snail Lymnaea stagnalis. Journal of Molluscan Studies, 62, 483-494.

(Manuscript received September 22, 2003; revision accepted for publication March 17, 2004.) 